\title{
Non-target and suspect characterisation of organic contaminants in Arctic air - Part 2: Application of a new tool for identification and prioritisation of chemicals of emerging Arctic concern in air
}

\author{
Laura Röhler $^{1,2}$, Martin Schlabach ${ }^{2}$, Peter Haglund ${ }^{3}$, Knut Breivik ${ }^{4,5}$, Roland Kallenborn ${ }^{1}$, and \\ Pernilla Bohlin-Nizzetto ${ }^{2}$ \\ ${ }^{1}$ Faculty of Chemistry, Biotechnology and Food Sciences (KBM), Norwegian University of Life Sciences, Ås, Norway \\ ${ }^{2}$ Department of Environmental Chemistry, NILU - Norwegian Institute for Air Research, Kjeller, Norway \\ ${ }^{3}$ Department of Chemistry, University of Umeå, Umeå, Sweden \\ ${ }^{4}$ Department of Atmosphere and Climate, NILU - Norwegian Institute for Air Research, Kjeller, Norway \\ ${ }^{5}$ Department of Chemistry, University of Oslo, Oslo, Norway
}

Correspondence: Laura Röhler (laura.rohler@nmbu.no)

Received: 8 February 2020 - Discussion started: 13 February 2020

Revised: 11 May 2020 - Accepted: 26 May 2020 - Published: 29 July 2020

\begin{abstract}
The Norwegian Arctic possesses a unique environment for the detection of new potential chemicals of emerging Arctic concern (CEACs) due to remoteness, sparse population and the low number of local contamination sources. Hence, a contaminant present in Arctic air is still considered a priority indication for its environmental stability and environmental mobility. Today, legacy persistent organic pollutants (POPs) and related conventional environmental pollutants are already well-studied because of their identification as Arctic pollutants in the 1980s. Many of them are implemented and reported in various national and international monitoring activities including the Arctic Monitoring and Assessment Programme (AMAP). These standard monitoring schemes, however, are based on compound-specific quantitative analytical methods. Under such conditions, the possibility for the identification of hitherto unidentified contaminants is limited and random at best. Today, new and advanced technological developments allow a broader, unspecific analytical approach as either targeted multicomponent analysis or suspect and non-target screening strategies. In order to facilitate such a wide range of compounds, a widescope sample clean-up method for high-volume air samples based on a combination of adsorbents was applied, followed by comprehensive two-dimensional gas chromatography separation and low-resolution time-of-flight mass spectrometric detection $(\mathrm{GC} \times \mathrm{GC}-\mathrm{LRMS})$. During the study re-
\end{abstract}

ported here, simultaneous non-target and suspect screening were applied. The detection of over 700 compounds of interest in the particle phase and over 1200 compounds in the gaseous phase is reported. Of those, 62 compounds were confirmed with reference standards and 90 compounds with a probable structure (based upon mass spectrometric interpretation and library spectrum comparison). These included compounds already detected in Arctic matrices and compounds not detected previously (see also Fig. 1). In addition, 241 compounds were assigned a tentative structure or compound class. Hitherto unknown halogenated compounds, which are not listed in the mass spectral libraries used, were also detected and partly identified.

\section{Introduction}

A high number of organic chemicals is used today in large quantities. By 2019, the Chemical Abstracts Service (CAS) registry ${ }^{\mathrm{SM}}$ contained more than 156 million unique inorganic and organic chemicals. This is $50 \%$ more than in 2015, when CAS was celebrating 100 million registered compounds (Wang, 2015). For the effective regional control of chemicals in commerce, the REACH register was introduced in the EU region (EC regulation no. 1907/2006 of the European Parliament and of the Council concerning the registra- 


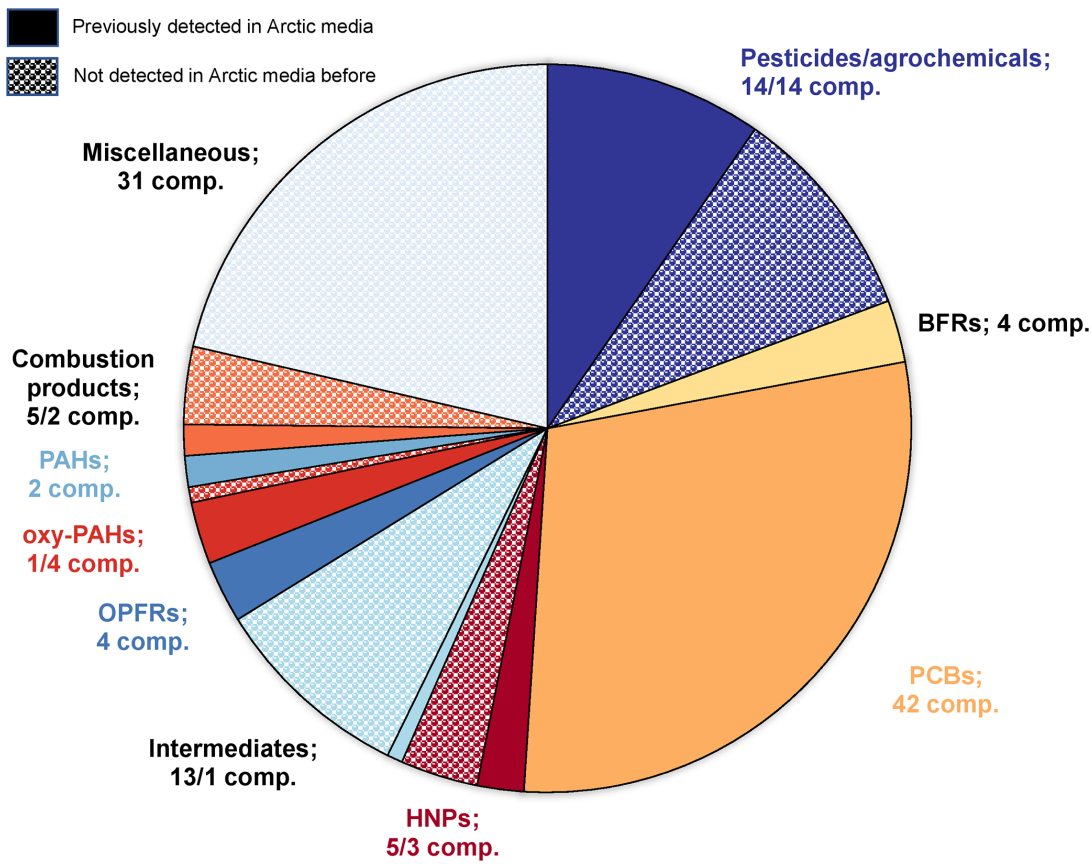

Figure 1. Graphical abstract, summary of compounds confirmed with reference standards and compounds with tentative structure.

tion, evaluation, authorisation and restriction of chemicals) managed by the European Chemicals Agency (European Parliament, 2018). REACH has only classified about 2000 substances (about $40 \%$ of chemicals registered with a production volume above $100 \mathrm{tyr}^{-1}$ ) into classes of high concern. Such chemicals were identified as carcinogenic, mutagenic, toxic for reproduction (CMRs), persistent, bioaccumulative and toxic (PBT), very persistent and very bioaccumulative (vPvB), and/or endocrine disruptors (EDCs) (data status May 2018; ECHA, 2019a). The assessment of chemicals with lower production volumes will follow. A considerable amount of organic chemicals is released into the environment by various pathways including insufficient waste management, direct application (e.g. agriculture, structure treatment), unintended by-products from large-scale production lines, and primary emission and/or releases from products and applications. Some of these organic chemicals are persistent and can migrate over long distances, ultimately reaching remote areas, such as the Arctic (Lebedev et al., 2018; Macdonald et al., 2000, 2005; Genualdi et al., 2011; Barrie et al., 1992). An important pathway for the long-range transport of persistent organic chemicals is via the atmosphere (Xiao et al., 2012; Genualdi et al., 2011; Hung et al., 2010; MacLeod et al., 2005; Koziol and Pudykiewicz, 2001; Barrie et al., 1992). Environmental persistence and long-range atmospheric transport potential (LRATP) (Zhang et al., 2010; Czub et al., 2008) are two hazard criteria which characterise persistent organic pollutants (POPs). POPs are considered to be priority pollutants, and their use and production is regulated through international agreements, such as the
Stockholm Convention on POPs and the Aarhus protocol on POPs under the Convention on Long-range Transboundary Air Pollution (CLRTAP) (UNEP, 2009b; UNECE, 1998). In order to evaluate the effectiveness of these agreements aiming at reducing human and environmental exposure to POPs (Fiedler et al., 2019), air monitoring strategies for legacy POPs have been established on national, regional and global levels. Examples are the European Monitoring and Evaluation Programme (EMEP, 2019) for the Aarhus protocol on POPs (UNECE, 1998), the Global Monitoring Plan (GMP) for the Stockholm Convention (UNEP, 2009a), and the Arctic Monitoring and Assessment Programme AMAP (2019) for the Arctic. Within these, the air monitoring of POPs in remote areas including the polar regions is used to study the long-range atmospheric transport of POPs to remote areas, and such knowledge is considered vital for the understanding of the environmental behaviour of POPs and further international POP regulation. Recently, chemicals of emerging Arctic concern (CEACs) (AMAP, 2017), including new flame retardants, plasticisers, per- and polyfluoroalkyl substances (PFAS), pharmaceuticals and personal care products (PPCPs), current-use pesticides (CUPs), and others, have received increased attention within AMAP. Selected CEACs have already been included in some of the national and regional air monitoring programmes in the Arctic (AMAP, 2009, 2017). Measurements of CEACs in the Arctic provide authorities with crucial knowledge supporting adequate policy measures and, if necessary, national or international regulations coming into place. In addition, it is important to identify new CEACs in the Arctic at an early stage. While this 
is often accomplished using biotic matrices, there is also a need for measurements in abiotic matrices like air as not all CEACs bioaccumulate but are still persistent and transported over long distances. Non-target and suspect screening (NTS and SUS) approaches represent promising strategies for the identification of so-far unidentified CEACs. However, standard sampling and analytical methods used for the targeted monitoring of POPs in air are not necessarily suitable for non-target analyses, and methodological challenges remain to be solved. For example, some CEACs may have similar properties to legacy POPs, while others might be less stable under certain conditions, such as being acid labile (e.g. some flame retardants, cyclic methyl siloxanes and some legacy POPs like dieldrin and related compounds) (Röhler et al., 2020). It is therefore important to develop nondestructive sample clean-up procedures, e.g. without sulfuric acid, to preserve an expanded range of compounds for SUS and NTS strategies in atmospheric samples. As a natural consequence of a wide-scope sample clean-up method, the resulting analytical extracts contain a larger load of interfering background matrix. It is therefore essential to increase the separation power of the instrumental analysis. This could be achieved by high-resolution chromatographic separation and/or high-resolution mass separation, i.e. high-resolution mass spectrometry (HRMS) methods.

In this study, a new non-destructive, wide-scope sample clean-up procedure and a powerful instrumental analysis method were applied to high-volume air samples from an Arctic background monitoring station, aiming at identifying regulated POPs, known CEACs, and emerging or new CEACs. The final separation and detection method was comprehensive two-dimensional gas chromatography $(\mathrm{GC} \times \mathrm{GC})$, which offers enhanced peak capacity compared to conventional GC and a better separation of matrix residues from analytes, and low-resolution time-of-flight mass spectrometry (LRMS) (Röhler et al., 2020). New potential CEACs were evaluated by comparing them to the PBT classification of the Stockholm Convention (UNEP, 2009b) with a focus on long-range atmospheric transport potential (LRATP).

\section{Experimental section}

\subsection{Air sampling and sample clean-up}

Two air samples were collected at the Zeppelin Observatory on Svalbard $\left(78^{\circ} 55^{\prime} \mathrm{N}, 11^{\circ} 53^{\prime} \mathrm{E}\right.$; $474 \mathrm{~m}$ a.s.1.) in December 2015. Zeppelin is a Norwegian background station providing environmental monitoring data, including organic environmental pollutants, to many national authorities and international monitoring programmes: EMEP, AMAP and GMP. The particle phase of the air samples was collected on glass-fibre filters (GFFs; $142 \mathrm{~mm}$ i.d.; cut-off $10 \mu \mathrm{m}$ ) and the gas phase was collected on polyurethane foam (PUF) plugs
(11 $\mathrm{cm}$ in diameter, $5 \mathrm{~cm}$ in height) using high-volume air samplers (average $25 \mathrm{~m}^{3} \mathrm{~h}^{-1}$ ). The sampling time was $4-5 \mathrm{~d}$, resulting in sample volumes of 2700 and $3500 \mathrm{~m}^{3}$. Details on the sampling methodology can be found in Kallenborn et al. (2013).

Before extraction, the PUFs from the two air samples were combined in one Soxhlet extractor and spiked with internal standards (ISTDs; details in Table S1 in the Supplement). The same was done for GFFs from the two air samples. PUFs and GFFs were Soxhlet-extracted separately for $8 \mathrm{~h}$ in acetone $/ n$-hexane $(1: 1 v / v)$. This resulted in one pooled PUF extract and one pooled GFF extract. The individual extracts were reduced to $0.5 \mathrm{~mL}$ with a Zymark TurboVap and solvent-exchanged to isooctane. For clean-up, threelayer liquid chromatography columns were used, with the bottom layer consisting of a mixture of Z-Sep ${ }^{+}$and DSC-18, the middle layer of Florisil, and the top layer of sodium sulfate. Samples were applied in isooctane and eluted with acetonitrile $(\mathrm{ACN}) / 0.5 \%$ citric acid $(w / w)$. Details about the sample clean-up can be found in the Supplement and Röhler et al. (2020).

\subsection{GC x GC-LRMS analysis}

The samples were analysed using a LECO Pegasus ${ }^{\circledR} 4 \mathrm{D}$ (St. Joseph, MI, USA) GC $\times$ GC-LRMS system operating in EI mode. The GC was equipped with a Restek (Bellefonte, PA, USA) Siltek guard column ( $4 \mathrm{~m}, 0.25 \mathrm{~mm}$ ), an SGE (Trajan Scientific and Medical, Ringwood, VIC, Australia) BPX$50(25 \mathrm{~m}, 0.25 \mathrm{~mm}, 0.25 \mu \mathrm{m})$ first-dimension column, and an Agilent J\&W (Folsom, CA, USA) VF-1ms ( $1.5 \mathrm{~m}, 0.15 \mathrm{~mm}$, $0.15 \mu \mathrm{m})$ second-dimension column. Helium (5.0 quality; Nippon Gases Norge AS, Oslo, Norway) was used as a carrier gas with a constant flow of $1 \mathrm{~mL} \mathrm{~min}^{-1}$. A total of $3 \mu \mathrm{L}$ of each extract was injected into a PTV (programmed temperature vaporiser) inlet operating in solvent vent mode. For the identification of unknown halogenated compounds (see Sect. 3.7), the samples were also analysed using a LECO GCHRT GC $\times$ GC-HRMS instrument operating under the same conditions described above for the GC $\times$ GC-LRMS analyses. Details on chromatographic conditions can be found in the Supplement.

\subsection{Quality control}

Laboratory blanks, consisting of unexposed PUFs and GFFs, were extracted, cleaned and analysed according to the same sample preparation scheme as the exposed samples. The blanks were used for quality assurance to ensure that identified and/or reported compounds have their origin in the collected air sample and do not appear in the blank samples above predefined levels (see Sect. 2.4). This means that compounds need to exceed the area threshold of a factor $100 \mathrm{com}$ pared to the area in the sample blanks. 
The ISTDs, which cover a wide area of the $\mathrm{GC} \times \mathrm{GC}$ chromatogram, were not used for target quantification but for quality assurance and sample normalisation. For example, the early eluting ISTDs (e.g. ${ }^{13} \mathrm{C}_{6}$ labelled hexachlorobenzene (HCB) or ${ }^{2} \mathrm{H}_{10}$-labelled phenanthrene) help to identify potential evaporative losses during clean-up and volume reduction, and the ${ }^{13} \mathrm{C}_{12}$-labelled $\quad p, p^{\prime}$-dichlorodiphenyltrichloroethane ( $p, p^{\prime}$-DDT) ISTD provides information about possible matrix effects in the injector and/or the GC column due to its higher thermal degradation potential. Thus, the $p, p^{\prime}$-dichlorodiphenyldichloroethylene $/ p, p^{\prime}$ dichlorodiphenyldichloroethane $\quad\left(p, p^{\prime}\right.$-DDE $/ p, p^{\prime}$-DDD $)$ ratio was used for the identification of injector losses. A comprehensive recovery test was done by Röhler et al. (2020) to investigate the applicability of this wide-scope sample clean-up method.

\subsection{Data processing and post-acquisition data treatment}

For GC $\times$ GC-LRMS system control, data analysis and processing, LECO $^{\circledR}$ ChromaTOF $^{\circledR}$ software (V 4.50.8) was used, including its advanced features: Statistical Compare and Scripts. Several in-house libraries with mass spectra of reference standards were used, including ${ }^{13} \mathrm{C} /{ }^{2} \mathrm{H}$-labelled ISTDs, the National Institute of Standards and Technology (NIST) 2014 mass spectral library, the Scientific Working Group for the Analysis of Seized Drugs (SWGdrug; Oulton, 2019) mass spectral library, and a customised library with selected spectra from NIST14 for suspect screening for the tentative identification of detected compounds. To create the customised library with selected spectra from NIST14, all mass spectra of compounds from NIST14, which are listed on relevant suspect lists for the Arctic (Reppas-Chrysovitsinos et al., 2017; Brown and Wania, 2008; Coscollà et al., 2011; Hoferkamp et al., 2010; Howard and Muir, 2010; NORMAN network, 2019; Vorkamp and Rigét, 2014; Zhong et al., 2012), were copied to an own library file for more efficient suspect screening. This customised library was useful to detect and flag potential suspects during data processing. More details can be found in Röhler et al. (2020), and a short description of how the data from suspect lists got aligned with our peak table and how the suspect MS libraries were built can be found in the Supplement.

The identification level classification concept of Schymanski et al. (2015), originally developed for liquid chromatography (LC)-HRMS data, defines a common set of rules for harmonised communication of identification confidences of results from different SUS and NTS studies. Due to the lack of HRMS data in the current study, this level classification concept had to be slightly adjusted to account for the limitations of LRMS data (Fig. 2); see Röhler et al. (2020). As LRMS analysis does not provide accurate masses, the low- est level of identification confidence, Level 5 (L5), is defined as peaks of interest, which are only characterised by retention time and a mass spectrum and not by tentative molecular weights. The remaining levels for identification confidence with LRMS are in line with the original concept of Schymanski et al. (2015): Level 4 (L4), defined by a possible molecular formula (e.g. a plausible molecular formula could be assigned to various compound classes) or a halogen cluster detected without a match to the MS libraries used. For Level 3 (L3), the group of tentative candidates identified as a substructure and/or class, a certain base structure is possible, e.g. the MS shows fragment patterns of a polycyclic aromatic hydrocarbon $(\mathrm{PAH})$ with a plausible molecular formula, but several alternative structures are possible. Level 2 (L2) is the group of probable structures based on good library matches and additional evidence, e.g. the position or grouping on the two-dimensional GC $\times$ GC plan. Level 1 (L1) is defined by compounds confirmed by external reference standards. We introduced an additional Level 0 (L0) for compounds confirmed by ISTDs and for which target quantification could be performed together with SUS and NTS. Target quantification was, however, not a primary aim of this study.

During SUS and NTS data processing (Fig. 3), the forward-match percentage to the mass spectrum (MS) library (ChromaTOF uses the NIST composite algorithm; see Samokhin et al., 2015) entry was used to reduce the number of peaks which require manual inspection (see Sect. 3.1 for numbers). This is a critical step in which potential compounds of interest may be lost, since the MS values from the NIST14 library are not identical to the MS obtained with the GC $\times$ GC-LRMS, probably due to the unit mass resolution of the instrument, generating mass artefacts as shown in Fig. 4. Compounds with higher mass defects, e.g. the brominated compounds, had non-acceptable spectra match quality (Fig. 4). It is possible that some compounds of interest were rejected during data processing due to a bad match of MS to the NIST14 MS library or custom suspect libraries. To minimise such losses of compounds with higher mass defects, visual basic scripts developed by Hilton et al. (2010) were applied for data processing. These scripts were specifically written for isotope clusters obtained from the instrument used. All compounds flagged by those scripts were checked manually. Furthermore, it was not possible to use available retention indices for further identification confidence due to the use of a medium polar GC column (BPX-50, $50 \%$ phenyl polysilphenylene-siloxane) as the first column for $\mathrm{GC} \times \mathrm{GC}$ separation instead of a non-polar (5\% phenyl) column, for which most of the retention indices are present in databases. In addition, there are limited concepts for the adaption of retention indices for $\mathrm{GC} \times \mathrm{GC}$ (e.g. Veenaas and Haglund, 2018; Mazur et al., 2018). This BPX-50 column, as the first column for $\mathrm{GC} \times \mathrm{GC}$ separation, was chosen to get a better separation of compounds of interest from an interfering background matrix and thus minimise negative effects on collected mass spectra. 


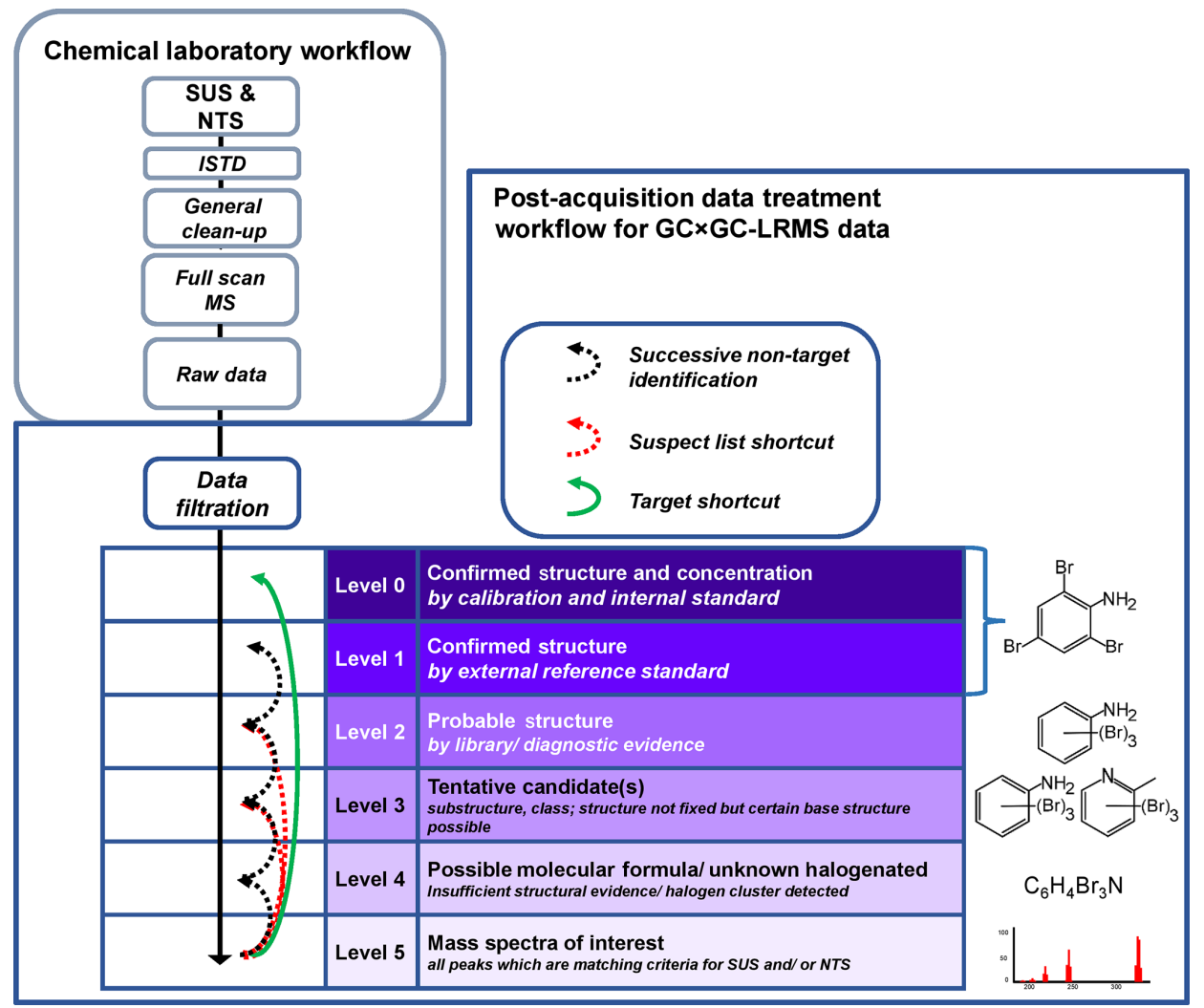

Figure 2. General strategy and identification confidence for GC $\times$ GC-LRMS. Adapted from Schymanski et al. (2015) and Röhler et al. (2020).

When a compound was flagged in the result list (L1-L5 lists, Fig. 3) for a manual check after data processing, additional plausibility checks were performed. These included the selectivity of the sampling and sample clean-up method as well as the complete sample analysis procedure. For instance, a compound should not degrade during sample processing (from sampling to analysis) or evaporate or sorb to the vial, injector or chromatographic column. The GC $\times$ GC retention times should also be reasonable; e.g. volatile compounds cannot elute at the end of the run and non-polar compounds cannot have a short second-dimension retention time. Furthermore, the area of a candidate in a sample should exceed the area threshold of factor $\geq 100$ in the corresponding sample blank to be kept in the peak table and not to be sorted out as a compound occurring from the blank sample. The higher threshold is necessary since areas are not adjusted for different sample volumes. The different sample extracts were visually adjusted to the same hight, before taking out aliquots for $\mathrm{GC} \times \mathrm{GC}$ analysis (uncertainty $\pm 10 \%$ ).

\subsection{Evaluation of long-range atmospheric transport potential}

The detection of a substance in air at Zeppelin does not provide conclusive evidence for long-range atmospheric trans- port. Yet, an organic chemical's potential for LRAT into the Arctic requires that it is sufficiently persistent in air. LRATP can be estimated from theoretical calculations. The key mechanism which is believed to degrade organic chemicals in the atmosphere is reaction with $\mathrm{OH}$ radicals. Because both concentrations of $\mathrm{OH}$ radicals and temperatures are very low during the polar night, the atmospheric halflife due to atmospheric reaction $\left(t_{1 / 2}\right)$ is predicted to be very long in comparison to lower latitudes (e.g. Webster et al., 1998). For a more realistic evaluation of LRATP, reaction half-lives in air therefore need to be adjusted to reflect the actual sampling conditions. Half-lives were adjusted using an equation from Wania et al. (2006), and we refer to the Supplement for details. To parameterise this equation, the reaction rates in air at $25^{\circ} \mathrm{C}$ were retrieved for $\mathrm{L} 0, \mathrm{~L} 1$ and $\mathrm{L} 2$ compounds from the EPI Suite software (U.S. EPA, 2019) and adjusted using the maximum temperature during sampling $\left(-2.4^{\circ} \mathrm{C}\right)$, an assumed $\mathrm{OH}$-radical concentration of $6 \times 10^{3} \mathrm{~mol} \mathrm{~cm}^{-3}$ and an assumed activation energy for reaction in air of $10000 \mathrm{~J} \mathrm{~mol}^{-1}$. Estimates of the $\mathrm{OH}$-radical concentration were based on a model developed by Bahm and Khalil (2004). However, this model does not predict $\mathrm{OH}$ radicals at latitudes higher than $45^{\circ} \mathrm{N}$, which crosses central Europe ( $[\mathrm{OH}]$ at $\left.45^{\circ} \mathrm{N}: 5 \times 10^{4} \mathrm{~mol} \mathrm{~cm}^{-3}\right)$, in December. Our samples were collected at $78^{\circ} \mathrm{N}$, and our assumed $\mathrm{OH}-$ 


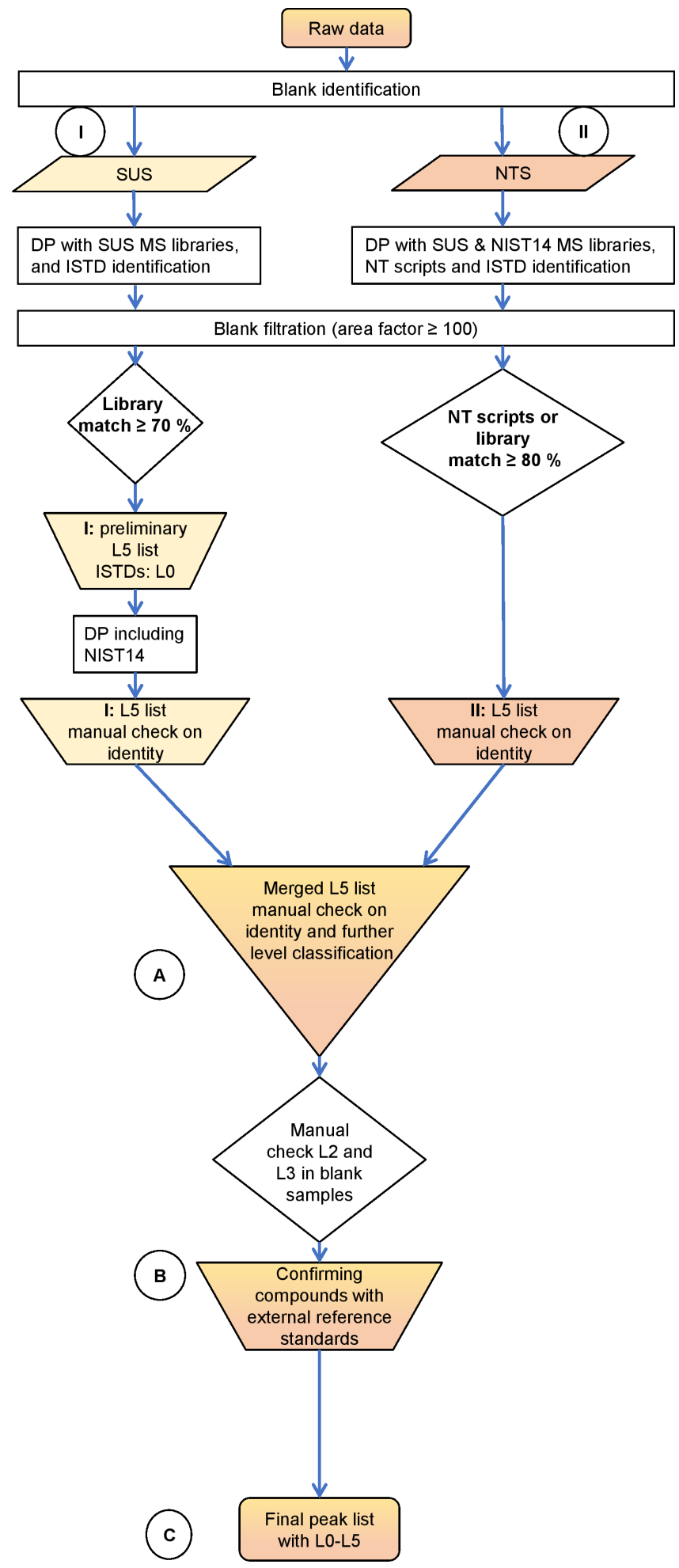

Figure 3. Data processing workflow for suspect and non-target screening. radical concentration of $6 \times 10^{3} \mathrm{~mol} \mathrm{~cm}^{-3}$ was chosen as an initial conservative estimate, keeping in mind that our analysed air samples include air masses which may have been transported from lower latitudes. Results from these theoretical calculations are discussed in Sect. 3.5.3 and shown in the Supplement (Table S3 and the Excel file).

\section{Results and discussion}

\subsection{Number of detected and classified compounds in Arctic air}

By applying the wide-scope clean-up based on C18 silica and Z-Sep ${ }^{+}$combined with Florisil to the air sample extracts from PUFs and GFFs, we were able to expand the chemical domain covered compared to established target POP analysis methods, which generally are using concentrated sulfuric acid. Our method covers a broad spectrum of polarity, has sufficient matrix removal, and is for the first time applied to Arctic air samples for the detection and identification of known and new potential CEACs. Previously, this method was successfully applied to air samples from southern Norway (Röhler et al., 2020).

It was possible to detect and classify over 700 compounds in the particle phase (GFF samples) and over 1200 compounds in the gas phase (PUF samples) as L5 with our classification and sorting method out of over 16000 features in GFF and almost 20000 features for PUF (for details on the peak reduction during data processing for SUS and NTS, see Fig. S1 in the Supplement). The higher number of gasphase compounds was expected since particle-related compounds collected on GFFs may have a lower LRATP compared to gas-phase-related compounds collected on PUFs. Of these L5 compounds, approximately 200 compounds in GFFs and approximately 400 compounds in PUFs could be further classified to L4, L3 or L2 (Fig. 5). As the structures of the remaining L5 compounds remain unknown, these compounds are not discussed any further. In total, 65 compounds (14 / 51 GFF / PUF) were classified as L4. Many compounds of the L4 class could be identified as unknown halogenated compounds because a halogen pattern was observed, but no matches in MS libraries were found (12 / 29 GFF / PUF). For the remaining L4 compounds, only a possible molecular formula could be assigned. As L3, 241 compounds (95 / 146 GFF / PUF) could be classified, including two major subgroups: polycyclic aromatic compounds (PACs) and phthalates (see Fig. 6). The PAC subgroup include many PAHs. A total of 90 compounds reached L2 (20 / 70 GFF / PUF), and 41 of the compounds in PUF were PCBs with two to seven chlorine substituents. By analysing reference standards under identical conditions as the air samples, 56 compounds could be classified as L1 (14 / 42 GFF / PUF) (Table 1). Furthermore, six compounds could be identified and confirmed with ISTDs to L0 in the PUF sample (only traces in the GFF sam- 


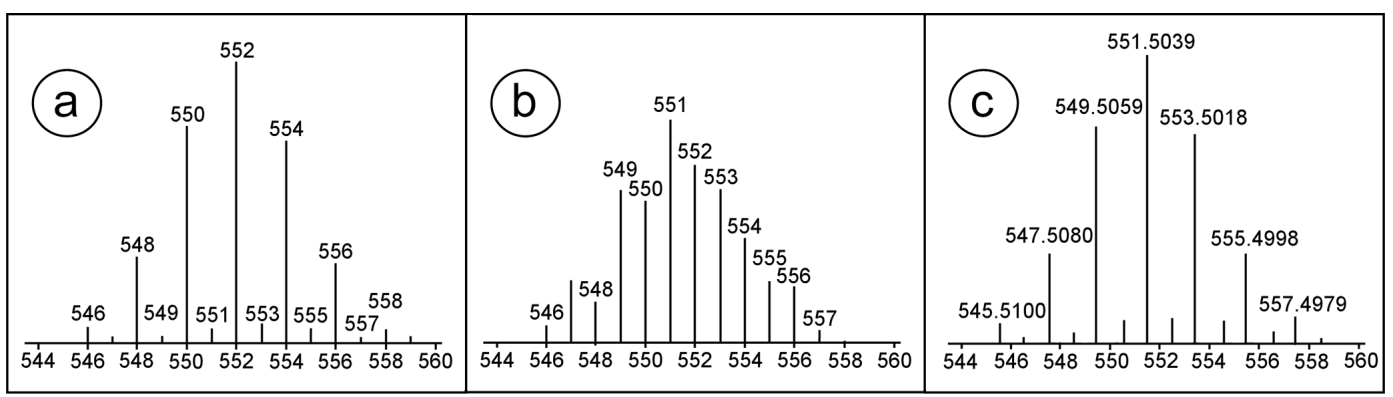

Figure 4. (a) Isotope cluster of hexabromobenzene (HBB) in NIST14, (b) own measured HBB on GC $\times$ GC-LRMS and (c) HRMS isotope cluster HBB (Röhler et al., 2020).
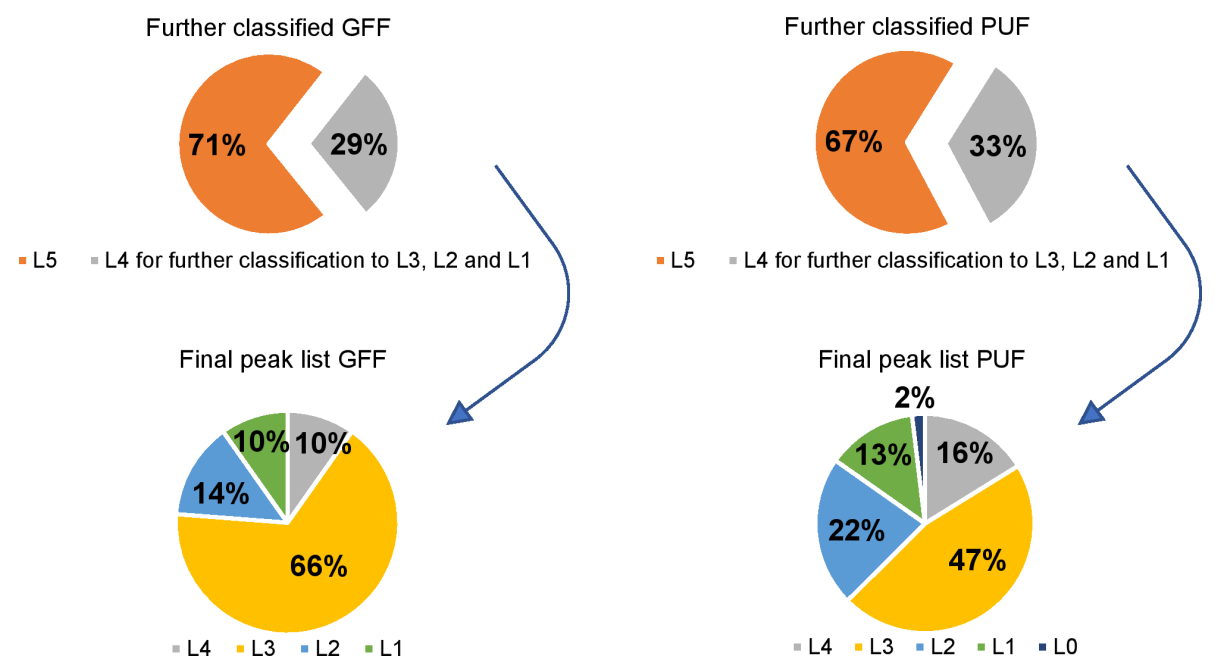

Figure 5. Distribution of L0-L5 compounds in the GFF and PUF sample.

ple). Of the 56 confirmed L1 compounds, seven were common to the GFF and PUF sample. Importantly, a compound not positively confirmed by this method does not necessarily mean that it does not occur in Arctic air.

As shown in Table 1, 39 of 56 compounds that were classified as L1 are listed in one or more suspect lists (Reppas-Chrysovitsinos et al., 2017; Brown and Wania, 2008; Coscollà et al., 2011; Hoferkamp et al., 2010; Howard and Muir, 2010; NORMAN network, 2019; Vorkamp and Rigét, 2014; Zhong et al., 2012) or self-built suspect libraries. From L2 compounds, 17 compounds resemble compounds in one or more suspect lists. Since L2 compounds are not confirmed with reference standards, those compounds might be different isomers than those listed in the Supplement, and thus matches to suspect lists could be different for L2 compounds.

For a better understanding of the importance of our findings at L0, L1 and L2, these compounds were further arranged into four groups. These groups are (i) legacy POPs and PAHs, (ii) CEACs defined in the AMAP (2017) report, (iii) organic compounds previously detected in Arctic media, and (iv) new potential CEACs not reported in Arctic media to date (October 2019). The new potential CEAC group was split into two subgroups: those with an estimated LRATP and those without. The default LRATP estimates are based on the EPI Suite software (U.S. EPA, 2019), reflecting standardised environmental conditions $\left(t_{1 / 2}\right.$ (air) at $25^{\circ} \mathrm{C}, 12 \mathrm{~h}$ days and a hydroxyl radical concentration of $1.6 \times 10^{6} \mathrm{OH} \mathrm{cm}^{-3}$ ), and the results compared with the criteria in the Stockholm Convention (UNEP, 2009b) that substances with $t_{1 / 2}$ (air) exceeding $2 \mathrm{~d}$ have LRATP. A complete table with all compounds identified, including physical-chemical properties from EPI Suite, the adjusted half-life in air during sampling (Eqs. S1 and S2 in the Supplement), usage and information from previous reports on occurrence in Arctic environments, toxicity, and presence on high production volume (HPV) chemical lists for the EU and US, as well as further parameters for PBT classification (REACH and Stockholm conventions), can be found in the Supplement (Table S2 and the Excel file).

\subsection{Legacy POPs and PAHs}

The currently used method revealed 59 legacy POPs and PAHs as L0, L1 and L2, specifically hexachlorocyclo- 
Table 1. Overview of the L0-L4 compounds classified in Arctic air samples.

\begin{tabular}{|c|c|c|c|c|c|}
\hline Level & $\begin{array}{r}\text { Compounds } \\
\text { classified }\end{array}$ & PUF sample & GFF sample & $\begin{array}{r}\text { Common to PUF } \\
\text { and GFF }\end{array}$ & $\begin{array}{r}\text { Found in } \\
\text { suspect lists }\end{array}$ \\
\hline L0 & 6 & 6 & Only traces detected & 0 & 1 \\
\hline L1 & 56 & 42 & 14 & 7 & 39 \\
\hline $\mathrm{L} 2$ & 90 & 70 (41 PCBs) & 20 & 0 & $17^{\mathrm{a}}$ \\
\hline L3 & 241 & 146 & 95 & 0 & $-b$ \\
\hline L4 & 65 & 51 (29 unknown halogenated) & 14 (12 unknown halogenated) & 0 & $-\mathrm{b}$ \\
\hline
\end{tabular}

a Showing similarity to suspect lists, isomer not confirmed; ${ }^{\mathrm{b}}$ not applicable.

hexanes $(\alpha-\mathrm{HCH}$ and $\gamma-\mathrm{HCH}), \mathrm{HCB}$, pentachlorobenzene (PeCB), DDTs ( $o, p^{\prime}$-DDT, $p, p^{\prime}$-DDT and $p, p^{\prime}$-DDD), PCB153, dieldrin, trans-nonachlor, cis-chlordane, two polybrominated diphenyl ethers (PBDE-28 and PBDE-47), and a metabolite of heptachlor (heptachloro exo epoxide) (UNEP, 2009b) as L0 or L1. Furthermore, two PAHs, benzo[ghi]fluoranthene (L1) and naphthalene (L2), could be identified. Other PAHs were classified as L3 (PACs). Dieldrin and benzo[ghi]fluoranthene were common to GFF and PUF and had a GFF : PUF ratio according to peak area of $1: 8$ for dieldrin and $2: 1$ for benzo[ghi]fluoranthene. It was also possible to classify $41 \mathrm{PCB}$ congeners as L2. The finding of legacy POPs and PAHs, routinely measured at the same monitoring station using target methods, is an indirect validation of the method and indicates that the detection of other compounds with similar physical-chemical properties is trustworthy. From the assumption that a higher concentration of a compound gives a greater peak area, the detected legacy POPs could be correlated with a good match to the average concentrations of monitored legacy POPs at the Zeppelin station (Table 2) (Nizzetto and Aas, 2016). Pearson correlation analysis indicates a strong correlation $(r=0.978)$ that is significant different from zero $(p<0.001)$. Thus, the screening approach seems to give an indication of the relative concentrations (occurrence) of semi-volatile organic compounds in Arctic air.

\subsection{CEACs as defined by AMAP}

In total, 11 of the detected compounds are included as CEACs in the AMAP (2017) report or in ReppasChrysovitsinos et al. (2017). One was classified as L0, five were classified as L1 and five were classified as L2. The CEAC classified as L0 was the flame retardant hexabromobenzene (HBB) that has also been detected in air at the Zeppelin Observatory by target analyses as part of the Norwegian national air monitoring programme for long-range-transport atmospheric contaminants. Classified as L1 were two halogenated natural products (HNPs), 2,4,6tribromoanisole (TBA) and 2,4-dibromoanisole (2,4-DBA), the pesticide metabolite pentachloroanisole (PCA), the organophosphorus flame retardant (OPFR) tri(2-chloroethyl)
Table 2. Ranking of the most abundant POPs in this study (based on peak area) in comparison to concentrations from target analysis $\left(\mathrm{pg} \mathrm{m}^{-3}\right)$ in the Norwegian national monitoring programme of long-range-transport environmental contaminants (Nizzetto and Aas, 2016).

\begin{tabular}{lrr}
\hline Compound & $\begin{array}{r}\text { Area from } \\
\text { this study }\end{array}$ & $\begin{array}{r}\text { Average concentration } \\
\text { in December 2015 at } \\
\text { Zeppelin }\left(\mathrm{pg} \mathrm{m}^{-3} ;\right. \\
\text { Nizzetto and Aas, 2016) }\end{array}$ \\
\hline HCB & 8032400 & 80.8 \\
PeCB & 890100 & $25.1^{\mathrm{a}}$ \\
$\alpha$-HCH & 652200 & 3.25 \\
$p, p^{\prime}$-DDE & 297500 & 0.89 \\
$\gamma$-HCH & 177700 & 0.6 \\
$o, p^{\prime}$-DDT & 46700 & 0.16 \\
Dieldrin & 37700 & $-{ }^{\mathrm{b}}$ \\
trans-Nonachlor & 36900 & 0.37 \\
$c i s$-Chlordane & 36100 & 0.35 \\
Heptachloro exo epoxide & 25800 & $-{ }^{-}$ \\
$p, p^{\prime}$-DDT & 18800 & 0.11 \\
PCB-153 & 15100 & 0.15 \\
PBDE-47 & 9800 & 0.07 \\
PBDE-28 & 600 & 0.006 \\
\hline
\end{tabular}

${ }^{a}$ Not shown in report; ${ }^{b}$ non-acid stable compound and not included in Norwegian national air monitoring.

phosphate (TCEP), and the stimulant caffeine. The five L2 compounds were the BFR pentabromotoluene (PeBT), one isomer of TCEP, two isomers of tris(2-chloroisopropyl) phosphate (TCPP), and an isomer of dibromoanisole (DBA), likely the HNP 2,6-DBA. TBA is routinely measured in air at the Zeppelin Observatory as part of the Norwegian monitoring programme. TBA has also been reported in Arctic air from the Zeppelin station by Vetter et al. (2002). Bidleman et al. (2017a, b) detected 2,4-DBA and TBA at Pallas, Finland (Bidleman et al., 2017a), and at several locations in the Bothnian Bay region (Bidleman et al., 2017b). PCA is a pesticide metabolite originating from the biodegradation of pentachlorophenol, which is a pesticide and wood preservative (GovCanada, 2019; Su et al., 2008). PCA has previously been found in air at other AMAP sampling sites, like Alert, Canada, but not at Zeppelin, Svalbard (Su et al., 2008; 
Hung et al., 2010). The stimulant and food additive caffeine, also an intermediate for pharmaceuticals as well as perfumes, fragrances, personal care products and laboratory chemicals (ECHA, 2019c), was found in effluent and seawater from Longyearbyen (Kallenborn et al., 2018) but to our knowledge not in air samples. TCPP (ECHA, 2019i; Sühring et al., 2016) is one of the main substances which have replaced TCEP in Europe (Ireland/UK, 2008). TCPP and TCEP were detected in our GFF sample (i.e. particle phase), together with structurally related isomers. OPFRs have previously been detected in Arctic air from the Zeppelin Observatory (Nizzetto et al., 2018; Salamova et al., 2014).

\subsection{Organic compounds previously detected in Arctic media}

Besides legacy POPs and PAHs, as well as CEACs listed by AMAP, it was also possible to identify eight other organic compounds as L1 and classify one compound as L2. These nine compounds have previously been reported in Arctic samples. As L1 we found tetrachloroveratrole, octachlorostyrene (OCS), 1,2,3,4-tetrachlorobenzene, 1,9-benz-10-anthrone, 9-fluorenone, 9,10-anthraquinone and $4 \mathrm{H}$-cyclopenta[def]phenanthren-4-one. Only one isomer of tetrachloroveratrole was classified as L2. Tetrachloroveratrole and its isomer are both pesticide metabolites ( $\mathrm{Su}$ et al., 2008; GovCanada, 2019), while the others were either combustion products or oxidation products of PAHs (Kirchner et al., 2016; Su et al., 2008; Hung et al., 2010; Gubala et al., 1995; Singh et al., 2017; Karavalakis et al., 2010). 4H-Cyclopenta[def]phenanthren-4-one was common to GFF and PUF with a GFF: PUF ratio from peak areas of $1: 2$. Tetrachloroveratrole and OCS have been reported from other Arctic monitoring sites like Alert, Canada, but are not included in the Norwegian monitoring programme at the Zeppelin Observatory on Svalbard (Hung et al., 2010; Su et al., 2008). OCS has also been detected in air samples from the Alps (Kirchner et al., 2016), and 1,2,3,4-tetrachlorobenzene has been measured in sediments in Arctic Alaska (Gubala et al., 1995) but to our knowledge not in Arctic air before; 1,9-benz-10-anthrone, 9-fluorenone, 9,10-anthraquinone and 4H-cyclopenta[def]phenanthren-4-one have been reported in aerosols as total suspended particles from the Alert station, Canada (Singh et al., 2017). Besides that, they were detected, among further oxy- and nitro-PAHs, in the emissions from a local point source in Longyearbyen, Svalbard (coal-fired power plant) (Drotikova et al., 2020). Most of the known Arctic contaminants were classified as L1 as a result of available standards. Please note that most PAHs are classified as L3 compounds due to the lack of single reference standards. We assume that several of the known PAHs, previously detected in Arctic media, could be found among the PAHs classified as PACs in L3 (see Sect. 3.6).

\subsection{New potential chemicals of emerging Arctic concern}

It was possible to classify 73 new potential CEACs with a match to reference standards (L1) or probable structures (L2). These 73 compounds have, to our knowledge, never been previously reported in Arctic media. The complete list can be found in the Supplement (Excel file). Almost $40 \%$ of these new potential CEACs have LRATP according to the Stockholm Convention (UNEP, 2009b), with $t_{1 / 2}$ (air) exceeding $2 \mathrm{~d}$ using the standard values from the EPI Suite calculation (see Sect. 3.1.) Although those compounds were not reported in the Arctic environment before, local sources cannot be excluded for some of the identified compounds. Especially for compounds which might be of biogenic origin, i.e. methoxy-chloro compounds, and compounds with widespread use, the potential for local sources needs to be kept in mind. This study, however, is not designed to prove the potential influence of local sources on the overall contaminant patterns. Especially for compounds that could be HNPs, but for which we could not find any evidence that they have been detected in the Arctic before, further in-depth studies are required.

\subsubsection{Potential CEACs with LRATP}

Out of the total of 73 identified or tentatively identified new potential CEACs, 29 were classified as compounds with LRATP according to the Stockholm Convention criteria (UNEP, 2009b), with $t_{1 / 2}$ (air) exceeding $2 \mathrm{~d}$ using the standard values from the EPI Suite calculation. Of these, 6 compounds were detected in the GFF sample (two as L1 and four as L2), and 23 compounds were detected in the PUF sample (13 as L1 and 10 as L2); see Tables 3 and 4. Further information about these compounds can also be found in the Supplement (Excel file). As the identities of L2 compounds were not fully confirmed, no literature search was performed for previous reports on occurrence in Arctic environments.

In the GFF sample, one of the two L1 compounds was benzenesulfonamide (BSA), an industrial intermediate used for the synthesis of chemicals in commerce like pesticides, photochemical products, pharmaceuticals, sweeteners or dyes (ECHA, 2019e; Naccarato et al., 2014; Herrero et al., 2014). Since BSA occurs in many products, local sources cannot be excluded and further investigations are needed to confirm potential LRATP or local sources as a major contamination source of BSA in the sample investigated here. The other L1 compound identified in the GFF is a potential combustion product, 2-methyl-9,10-anthraquinone, which can have its origin in wood combustion (Czech et al., 2018; Lui et al., 2017; Vicente et al., 2016) or can be formed by atmospheric reactions (Alam et al., 2014). 2-Methyl-9,10anthraquinone is also an intermediate in the production of coating products, inks and toners, laboratory chemicals, and explosives; it is also used for the production of plastic prod- 
Table 3. Structure overview of L1 compounds classified as new potential CEACs with LRATP.

\begin{tabular}{|c|c|c|c|}
\hline Name/CAS/sample & Structure & Name/CAS/sample & Structure \\
\hline $\begin{array}{l}\text { Benzenesulfonamide (BSA)/ } \\
98-10-2 \\
\text { GFF (particle phase) }\end{array}$ & & $\begin{array}{l}\text { 2-Naphthalenecarbonitrile/ } \\
613-46-7 \\
\text { PUF (gas phase) }\end{array}$ & \\
\hline $\begin{array}{l}\text { 2-Methyl-9,10-Anthraquinone/ } \\
\text { 84-54-8 } \\
\text { GFF (particle phase) }\end{array}$ & & $\begin{array}{l}2,3,5,6-\text { Tetrachloropyridine/ } \\
2402-79-1 \\
\text { PUF (gas phase) }\end{array}$ & \\
\hline $\begin{array}{l}\text { 2,6-Dichlorobenzonitrile } \\
\text { (dichlorobenil)/ } \\
\text { 1194-65-6 } \\
\text { PUF (gas phase) }\end{array}$ & & $\begin{array}{l}\text { Pentachloropyridine/ } \\
2176-62-7 \\
\text { PUF (gas phase) }\end{array}$ & \\
\hline $\begin{array}{l}\text { 2,4-Dichlorobenzonitrile/ } \\
6574-98-7 \\
\text { PUF (gas phase) }\end{array}$ & & $\begin{array}{l}\text { 1,4-Benzenedicarbonitrile } \\
\text { (terephthalonitrile)/ } \\
623-26-7 \\
\text { PUF (gas phase) }\end{array}$ & \\
\hline $\begin{array}{l}\text { 1,4-Dichloro-2,5-dimethoxybenzene } \\
\text { (chloroneb)/ } \\
2675-77-6 \\
\text { PUF (gas phase) }\end{array}$ & & $\begin{array}{l}2^{\prime}, 3^{\prime}, 4^{\prime}-\text { Trichloroacetophenone/ } \\
13608-87-2 \\
\text { PUF (gas phase) }\end{array}$ & \\
\hline $\begin{array}{l}\text { 2-Chloro-6-(trichloromethyl)pyridine } \\
\text { (Nitrapyrin)/ } \\
\text { 1929-82-4 } \\
\text { PUF (gas phase) }\end{array}$ & & $\begin{array}{l}2,4,6-\text { Tribromoaniline/ } \\
147-82-0 \\
\text { PUF (gas phase) }\end{array}$ & \\
\hline $\begin{array}{l}\text { 2,4-Dichloroanisole/ } \\
\text { 553-82-2 } \\
\text { PUF (gas phase) }\end{array}$ & & $\begin{array}{l}\text { 2-Nitroanisole/ } \\
\text { 91-23-6 } \\
\text { PUF (gas phase) }\end{array}$ & \\
\hline $\begin{array}{l}2,4,6-\text { Trichloroanisole/ } \\
87-40-1 \\
\text { PUF (gas phase) }\end{array}$ & & & \\
\hline
\end{tabular}

Table 4. Overview of L2 compounds classified as new potential CEACs with LRATP.

\begin{tabular}{|c|c|c|}
\hline Name & Sample & Molecular formula \\
\hline 3,4-Dichloropropiophenone-related positional isomer ${ }^{\mathrm{a}}$ & GFF (particle phase) & $\mathrm{C}_{9} \mathrm{H}_{8} \mathrm{Cl}_{2} \mathrm{O}$ \\
\hline Diphenyl sulfone & GFF (particle phase) & $\mathrm{C}_{12} \mathrm{H}_{10} \mathrm{O}_{2} \mathrm{~S}$ \\
\hline Dibenzothiophene sulfone & GFF (particle phase) & $\mathrm{C}_{12} \mathrm{H}_{8} \mathrm{O}_{2} \mathrm{~S}$ \\
\hline$N$-(2-Cyanoethyl)- $N$-methyl-benzenesulfonamide & GFF (particle phase) & $\mathrm{C}_{10} \mathrm{H}_{12} \mathrm{~N}_{2} \mathrm{O}_{2} \mathrm{~S}$ \\
\hline Two chloroneb-related positional isomers ${ }^{\mathrm{b}}$ & PUF (gas phase) & $\mathrm{C}_{8} \mathrm{H}_{8} \mathrm{Cl}_{2} \mathrm{O}_{2}$ \\
\hline One chlorothalonil-related positional isomer ${ }^{\mathrm{c}}$ & PUF (gas phase) & $\mathrm{C}_{8} \mathrm{Cl}_{4} \mathrm{~N}_{2}$ \\
\hline Two trichloro-dimethoxybenzen isomers & PUF (gas phase) & $\mathrm{C}_{8} \mathrm{H}_{7} \mathrm{Cl}_{3} \mathrm{O}_{2}$ \\
\hline Two dichloro-methylanisole isomers & PUF (gas phase) & $\mathrm{C}_{8} \mathrm{H}_{8} \mathrm{Cl}_{2} \mathrm{O}$ \\
\hline One dibromo-dimethoxybenzene isomer & PUF (gas phase) & $\mathrm{C}_{8} \mathrm{H}_{8} \mathrm{Br}_{2} \mathrm{O}_{2}$ \\
\hline 1-Naphthalenecarbonitrile & PUF (gas phase) & $\mathrm{C}_{11} \mathrm{H}_{7} \mathrm{~N}$ \\
\hline One pentachloro-methylbenzene positional isomer ${ }^{\mathrm{d}}$ & PUF (gas phase) & $\mathrm{C}_{7} \mathrm{H}_{3} \mathrm{Cl}_{5}$ \\
\hline
\end{tabular}

${ }^{a}$ Retention times close, but not identical, to those of a 3,4-dichloropropiophenone standard. ${ }^{b}$ Retention times close, but not identical, to those of a chloroneb standard. ${ }^{c}$ Retention times close, but not identical, to those of a chlorothalonil standard. ${ }^{\mathrm{d}}$ Retention times close, but not identical, to those of a pentachlorotoluene standard. 
ucts (ECHA, 2019h). Besides those L1 compounds it was possible to detect one 3,4-dichloropropiophenone-related compound, likely a positional isomer, and three sulfurrelated compounds: diphenyl sulfone, dibenzothiophene sulfone and $N$-(2-cyanoethyl)- $N$-methyl-benzenesulfonamide; these were classified as L2 by MS library matching.

In the PUF sample, the pesticide dichlobenil (2,6dichlorobenzonitril) was identified, together with an isomer, 2,4-dichlorobenzonitrile (ECHA, 2019g), as L1. No information on commercial application and usage is found for 2,4dichlorobenzonitrile. Besides dichlobenil, another pesticide, chloroneb (1,4-dichloro-2,5-dimethoxybenzene) (U.S. EPA, 2005), was identified as L1, and two chloroneb-related compounds and one chlorothalonil-related compound, likely positional isomers of those, were assigned L2. The nitrification inhibitor nitrapyrine (2-chloro-6-(trichloromethyl)pyridine; L1) was identified in Arctic samples for the very first time (ECHA, 2019f; Woodward et al., 2019). Furthermore, two trichloro-dimethoxybenzenes, two dichloro-methylanisols and one dibromo-dimethoxybenzene were also assigned L2.

Biogenic origin cannot be excluded for halogenated methoxybenzenes. Local sources also cannot be excluded for the closely related 2,4-dichloroanisole and 2,4,6-trichloroanisole (both L1), potential metabolites of chlorophenol and chlorophenoxy pesticides, and also potential HNPs (Führer and Ballschmiter, 1998; Schenker et al., 2007; Bendig et al., 2013). 2-Naphthalenecarbonitrile, originating most probably from plastic combustion, e.g. ABS (acrylonitrile butadiene styrene) plastic or polyester fabrics (Moltó et al., 2006, 2009; Watanabe et al., 2007; Wang et al., 2007) or the bluing of steel (Stefanye, 1972), was identified as L1 and 1-naphthalenecarbonitrile as L2. A further group of compounds, confirmed with reference standards as L1, are intermediates with various application areas. 2,3,5,6Tetrachloropyridine and pentachloropyridine are intermediates occurring in the synthesis of the pesticides chlorpyrifos and triclopyr (Howard and Muir, 2010). Terephthalonitrile is identified as an intermediate for the production of the pesticide dacthal (Meng, 2012). $2^{\prime}, 3^{\prime}, 4^{\prime}$-Trichloroacetophenone is an intermediate for the production of various fungicides and pharmaceuticals (WOC, 2019). Not much is known about the use of 2,4,6-tribromoaniline, but it might be used in the synthesis of pharmaceuticals, agricultural pesticides and fireextinguishing agents (Labmonk, 2019). 2-Nitroanisole can have its origin in combustion processes or can be formed by atmospheric reactions (Stiborova, 2002). In 1993, large quantities of 2-nitroanisole were emitted into the air during an accident at the Höchst plant in Germany (Weyer et al., 2014). A pentachloro-methylbenzene-related compound, likely a positional isomer, was detected and assigned L2, but industrial uses are not known.

\subsubsection{Potential CEACs without LRATP}

Besides the new potential CEACs with LRATP described in the previous section, we could also identify 44 new potential CEACs which do not have a predicted LRATP according to the Stockholm Convention criteria (UNEP, 2009b), reflecting default standardised environmental conditions. Of these 44 new potential CEACs, 19 compounds were detected in the GFF sample (six as L1 and 13 as L2) and 25 compounds were detected in the PUF sample (11 as L1 and 14 as L2). An overview of L1 compounds without a predicted LRATP reflecting default environmental conditions can be found in Table 5. None of the new L1 potential CEACs have to our knowledge been previously detected in Arctic samples; only triallate was found once before in passive air samples from Arviat, Nunavut, Canada (western shore of Hudson Bay; $61^{\circ} \mathrm{N}$ ) (Messing et al., 2014), which is outside the Arctic Circle. Triallate is an agriculture pesticide and was detected in both GFF and PUF in our sample. Four of the six L1 compounds detected in the GFF sample were also found in the PUF sample at various GFF / PUF peak area ratios: $m$ terphenyl $1: 30$ (GFF : PUF ratio), triallate $1: 17$ (GFF : PUF ratio), dichlofluanid 1:3 (GFF: PUF ratio) and carbazole $1: 1$ (GFF : PUF ratio). The two remaining compounds, identified as L1 in the GFF sample, were 1,2-benzoanthraquinone and $6 \mathrm{H}-$-benzo[cd]pyren-6-one. Both are potential combustion products and can have their origin in wood or coal combustion (Czech et al., 2018; Lui et al., 2017; Vicente et al., 2016), or they can be formed by atmospheric reactions (Alam et al., 2014). As L2, we could, besides others, classify several positional isomers of reference standards which were analysed (see the Excel file in the Supplement for further details).

In the PUF it was possible to identify all three isomers of terphenyl $(o, m, p)$ usually applied as a technical mixture, while only $m$-terphenyl was also detected in the GFF. The commercial mixture of terphenyls is used as an industrial agent for heat storage and transfer as well as textile dye carriers and as an intermediate of non-spreading lubricants (Health Council of the Netherlands, 2002). During pyrolysis and the combustion of used black shorts (polyether fabric), all three terphenyl isomers were detected (Moltó et al., 2006). 4-Chloro-2-methylphenole (PCOC) is used by the industry as an intermediate for the production of phenoxy herbicides and is found as an impurity in the final commercial product (Hansen et al., 2002). For dichlofluanid, carbazole, 3-iodo-2-propynyl-butylcarbamate (IPBC) and 2-(methylmercapto)benzothiazole, local contamination sources cannot be excluded. Diclofluanid and IPBC are both used as wood preservatives, and carbazole is a constituent of coal tar (creosote). In addition to that, IPBC is used in cosmetics and personal care products (ECHA, 2019b, d), and carbazole is used in the production of carbazolecontaining polymers (PVK, or poly(- $N$-vinylcarbazole)) that are used in photovoltaic devices and semiconducting polymers (Zhao et al., 2017; Grazulevicius et al., 2003). Car- 
Table 5. Structure overview of L1 compounds classified as new potential CEACs without a predicted LRATP under standardised environmental conditions.

\begin{tabular}{|c|c|c|c|}
\hline Name/CAS/sample & Structure & Name/CAS/sample & Structure \\
\hline $\begin{array}{l}\text { 6H-Benzo }[c d] \text { pyren-6-one/ } \\
3074-00-8 \\
\text { GFF (particle phase) }\end{array}$ & & $\begin{array}{l}\text { 4-Chloro-2-methylphenole (PCOC)/ } \\
\text { 1570-64-5 } \\
\text { PUF (gas phase) }\end{array}$ & \\
\hline $\begin{array}{l}\text { Triallate/ } \\
2303-17-5 \\
\text { GFF and PUF }\end{array}$ & & $\begin{array}{l}\text { 3-Iodo-2-propynyl-butylcarbamate } \\
\text { (iodocarb, IPBC)/ } \\
\text { 55406-53-6 } \\
\text { PUF (gas phase) }\end{array}$ & \\
\hline $\begin{array}{l}\text { Carbazole/ } \\
86-74-8 \\
\text { GFF and PUF }\end{array}$ & & $\begin{array}{l}\text { MHC-1 } \\
\text { (2-bromo-1-bromomethyl-1,4-dichloro-5- } \\
\text { (2'-chloroethenyl)-5-methylcyclohexane)/ } \\
66321-24-2 \\
\text { PUF (gas phase) }\end{array}$ & \\
\hline $\begin{array}{l}m \text {-Terphenyl/ } \\
192-06-8 \\
\text { GFF and PUF }\end{array}$ & & $\begin{array}{l}\text { 2-bromo-3,5-dimethoxytoluene/ } \\
\text { 13321-73-8 } \\
\text { PUF (gas phase) }\end{array}$ & \\
\hline
\end{tabular}

bazole is also used in the production of pharmaceuticals (Zawadzka et al., 2015). 2-(Methylmercapto)benzothiazole is a major methylation product of 2-mercaptobenzothiazole, a commonly used vulcanisation accelerator in rubber car tires, shoes, cables, rubber gloves and toys (Herrero et al., 2014; Leng and Gries, 2017). Due to the widespread use of rubber products in and around the sampling station, a potential local origin cannot be excluded. Dichlofluanid and carbazole were detected in both the GFF and PUF sample, while IPBC and 2-(methylmercapto)benzothiazole were only in the PUF sample. The mixed halogenated compound MHC1 is an HNP emitted from marine natural sources. As confirmed earlier, the seaweed Plocamium cartilagineum produces large amounts of MHC-1 (Vetter et al., 2008). MHC-1 was, however, not detected in Zeppelin air samples reported in an earlier study (Vetter et al., 2002). Further studies are necessary to identify the origin of MHC-1 in the Arctic. No information was found on the industrial usage of 2-bromo3,5-dimethoxytoluene, but formation as HNP cannot be excluded, since chlorinated dimethoxytoluenes were previously identified in lichen (Elix et al., 1984).

\subsubsection{Estimated half-lives in air reflecting Arctic environmental conditions}

Our $t_{1 / 2}$ (air) is based on default values retrieved from EPI Suite (U.S. EPA, 2019). Standardised estimates are commonly used for the estimation of LRATP (Muir and Howard, 2006; Howard and Muir, 2010; Brown and Wania, 2008; Reppas-Chrysovitsinos et al., 2017). These default half-lives are likely underestimated when adjusted to Arctic environmental conditions. When adjusting the estimates of $t_{1 / 2}$ (air) 
Table 6. Half-life in air: standard values from EPI Suite and adjusted for Arctic conditions (Eqs. S1-S2) for selected compounds.

\begin{tabular}{llrr}
\hline Name & CAS & $\begin{array}{r}\text { Standard half-life } \\
(\text { days })\left(25^{\circ} \mathrm{C} ;\right.\end{array}$ & $\begin{array}{r}\text { Adjusted half-life } \\
(\text { days })\left(-2.4^{\circ} \mathrm{C} ;\right. \\
\left.6.0 \times 10^{3} \mathrm{~mol} \mathrm{~cm}^{-3}\right)\end{array}$ \\
\hline 9-Fluorenone & $486-25-9$ & 1.7 & 651 \\
$p, p^{\prime}$-DDE & $72-55-9$ & 1.4 & 541 \\
Dieldrin & $60-57-1$ & 1.2 & 437 \\
1,9-Benz-10-anthrone & $82-05-3$ & 0.6 & 223 \\
Caffeine & $58-08-2$ & 0.6 & 207 \\
TCIPP & $13674-84-5$ & 0.2 & 90 \\
TCEP & $115-96-8$ & 0.5 & 183 \\
Benzo[ghi]fluoranthene & $203-12-3$ & 0.2 & 65 \\
Naphthalene & $91-20-3$ & 0.5 & 186 \\
Tris(3-chloropropyl) phosphate & $1067-98-7$ & 0.1 & 55 \\
$m$-Terphenyl & $92-06-8$ & 0.8 & 159 \\
Dichlofluanid & $1085-98-9$ & 0.7 & 135 \\
IPBC & $55406-53-6$ & 0.4 & 79 \\
\hline
\end{tabular}

for the sampling temperature and assumed OH-radical concentrations in December (see Sect. 2.5), all compounds classified as L1 and L2 have an estimated $t_{1 / 2}$ (air) exceeding $2 \mathrm{~d}$. Results for selected compounds can be found in Table 6, and further results are in Table S3 and the Excel file in the Supplement. This supports our assumption that those new potential CEACs could be subject to LRAT as a result of enhanced persistence in air during Arctic winter. While influences from nearby sources cannot be excluded, those properties are relevant for two out of four hazard criteria defining a POP according to the Stockholm convention (UNEP, 2009b), suggesting they deserve further focus from the research and policy communities. While the selected numerical values used to predict adjusted reaction half-lives may be questioned, these data in combination with their findings in Arctic air samples suggest that LRATP cannot be excluded. While half-lives are prolonged under relevant Arctic conditions, we caution that our estimates do not account for differences in net atmospheric deposition among the substances studied, which may limit LRATP (e.g. Beyer et al., 2003).

\subsubsection{Comparison of findings in Arctic air to air samples from southern Norway}

For some compounds it was possible to compare findings from this study of Arctic air samples to findings of similar high-volume air samples from Birkenes in southern Norway (Röhler et al., 2020). The Birkenes Observatory is an EMEP monitoring station for background air, and the air samples were collected during April-May 2015. For a complete overview of compounds that were identified in both studies, see the Excel file in the Supplement. Among the new potential CEACs detected in Arctic air, it was also possible to find 5 of $15 \mathrm{~L} 1$ compounds with LRAT and 10 of 13 L1 compounds without LRAT in the Birkenes air. The

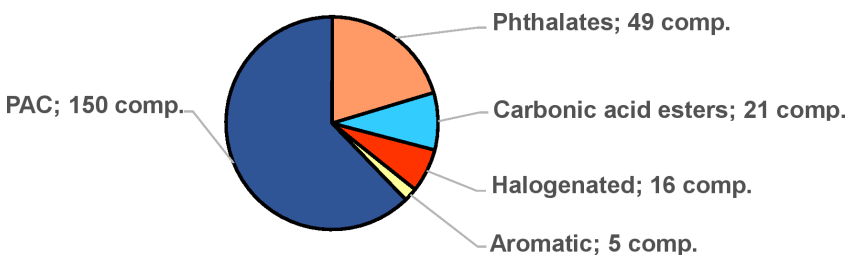

Figure 6. L3 compound groups.

identification of new potential CEACs in air samples from both southern Norway (Birkenes) and the Arctic (Zeppelin, Svalbard), combined with predictions of $t_{1 / 2}$ (air) which are adjusted to reflect actual environmental conditions, supports our assumption that these compounds may undergo LRAT.

\subsection{Summary for Level 3 compounds}

A large number of L3 compounds, as tentative candidates, were detected in the Arctic air samples. The bulk of them are PACs, primarily PAHs, substituted PAHs (e.g. alkane side chains), halogenated PAHs, and sulfur-, nitrogen- and oxygen-containing PAHs (Fig. 6). The tentatively identified compounds also include several phthalates, carbonic acid esters and miscellaneous halogenated compounds. The list of L3 compounds can be found in the Supplement (Excel file).

\subsection{Level 4 compounds}

The group of L4 compounds includes compounds with an assigned molecular formula and several unknown halogenated compounds, which did not match any of the MS values in the MS libraries used. The approximate molecular weight (nominal mass), the degree of halogenation and some major fragments could be extracted from the LRMS spectra (see the Excel file in the Supplement). Additional structural informa- 
Table 7. Unknown halogenated compounds with HRMS data.

\begin{tabular}{llll}
\hline Compound & $\begin{array}{l}\text { Accurate } \\
\text { mass }\end{array}$ & $\begin{array}{l}\text { Possible molecular formula } \\
\text { from MetFrag }\end{array}$ & $\begin{array}{l}\text { Formula supported by manual } \\
\text { fragment interpretation }\end{array}$ \\
\hline A\#9842 GFF & 256.0169 & $\mathrm{C}_{11} \mathrm{H}_{10} \mathrm{Cl}_{2} \mathrm{~N}_{2} \mathrm{O}$ & $\mathrm{C}_{11} \mathrm{H}_{10} \mathrm{Cl}_{2} \mathrm{~N}_{2} \mathrm{O}$ \\
\hline B\#11108 GFF & 230.0134 & $\mathrm{C}_{8} \mathrm{H}_{8} \mathrm{Cl}_{2} \mathrm{~N}_{4}$ & $\begin{array}{l}m / z \\
\mathrm{C}_{10} \mathrm{H}_{10} \mathrm{Cl}{ }_{2} \mathrm{NO}\end{array}$ \\
\hline C\#4444 PUF & 299.8372 & $\begin{array}{l}\mathrm{C}_{7} \mathrm{H}_{5} \mathrm{Br}_{2} \mathrm{ClO} \\
\mathrm{C}_{6} \mathrm{H}_{5} \mathrm{Br}_{2} \mathrm{O}_{2} \mathrm{P}\end{array}$ & $\mathrm{C}_{7} \mathrm{H}_{5} \mathrm{Br}_{2} \mathrm{ClO}$ \\
\hline D\#5672 PUF & 220.0053 & $\begin{array}{l}\mathrm{C}_{9} \mathrm{H}_{10} \mathrm{Cl}_{2} \mathrm{O}_{2} \\
\mathrm{C}_{8} \mathrm{H}_{10} \mathrm{ClO}_{3} \mathrm{P}\end{array}$ & $\mathrm{C}_{9} \mathrm{H}_{10} \mathrm{Cl}_{2} \mathrm{O}_{2}$ \\
& & & \\
\hline
\end{tabular}

tion was obtained using $\mathrm{GC} \times \mathrm{GC}-\mathrm{HRMS}$ for some of the unknown halogenated compounds.

The acquired accurate mass spectra from HRMS (see the Supplement for HRMS spectra) were processed using MetFrag software (MetFrag, 2019; Ruttkies et al., 2016), and possible molecular formulas were generated (Table 7).

After searching SciFinder ${ }^{\circledR}$ with possible molecular formulas and identified substructures from the mass spectra, it was possible to find structure suggestions for several of the unknown halogenated compounds analysed with HRMS. The number of citations of a compound in SciFinder could give a further limitation of possible structures. Since the mass spectra do not occur in the NIST14 MS library, the found compound might be a less cited compound or might not have been registered or assigned a CAS number, and it is not yet listed in the CAS registry in SciFinder. Using HRMS and SciFinder data, additional structural information could be extracted for four unknown halogenated compounds (Table 7 and Figs. S2-S7) originally classified as L4. Two of the compounds were tentatively identified as methoxylated halogenated benzenes, one dibromo-monochloro-anisole and one dichloro-methyl-dimethoxy-benzene. Several structurally related compounds were found among the potential CEACs with a default LRATP (see Sect. 3.5.1 and Table 4) of which one, chloroneb, was assigned L1 confidence, which supports the tentative structure assignments and qualifies the two for L3.

\section{Conclusions}

By applying a dedicated non-target and suspect screening method based on a non-destructive sample clean-up method (excluding acid treatment) combined with $\mathrm{GC} \times \mathrm{GC}$-LRMS to high-volume air samples from Arctic Svalbard, a large number of known and new potential CEACs could be identified and prioritised. During this study, 73 new potential CEACs (compounds previously not reported in Arctic environments) were classified at confidence level L1 or L2, which indicates that comprehensive suspect and non-target screening can reveal new potential CEACs that might need to be monitored or risk-assessed. All these compounds are predicted to have atmospheric reaction half-lives exceeding $2 \mathrm{~d}$ if these are adjusted to reflect actual environmental conditions during sampling. Reaction half-lives reflecting standardised environmental conditions (e.g. $25^{\circ} \mathrm{C}$ ) are thus poor predictors for persistence in the Arctic environment. The study reported here underpins the importance of combining model estimates with empirical measurements for the environmental assessment of chemicals. The newly identified organic CEACs from this study are recommended for inclusion in regulatory monitoring strategies and for target-specific analytical methods. Although the applied identification method is a promising tool for the identification of new priority pollutants, we do not consider the current study to be exhaustive. Further in-depth studies carried out using GC $\times$ GC-HRMS are expected to provide additional information about CEACs not yet included in MS libraries. Those should preferably use a column set featuring a non-polar first-dimension column, which allows for comparisons to retention time databases or retention index prediction data (Veenaas and Haglund, 2018) in order to accept or reject the candidate structures of hitherto unknown CEACs.

Data availability. All necessary data are provided in the Excel file in the Supplement.

Supplement. The supplement related to this article is available online at: https://doi.org/10.5194/acp-20-9031-2020-supplement.

Author contributions. LR, MS, PBN and RK developed the idea behind this study. LR performed chemical work and analysis, created the figures, and wrote the paper. MS and PBN provided guidance and contributed to the paper preparation. PH provided guidance, conducted HRMS measurements and contributed to the paper preparation. KB provided guidance on theoretical calculations and contributed to the paper preparation. RK provided financial support and academic guidance, as well as contributing to the paper preparation. All authors read and approved the submitted paper. 
Competing interests. The authors declare that they have no conflict of interest.

Acknowledgements. Compound structures were created using ChemOffice19 (PerkinElmerInformatics, 2019). LogP and $\log \mathrm{D}$ values were created using JChem for Excel (ChemAxon, 2019).

This study was funded by the following: NMBU, the Norwegian University of Life Sciences, Ås, with an internal PhD grant; NILU, the Norwegian Institute for Air Research, Kjeller; and the Norwegian Ministry of Climate and Environment through two Strategic Institute Programmes granted by the Norwegian Research Council ("Speciation and quantification of emerging pollutants" and "New measurement methods for emerging organic pollutants"). Knut Breivik received support from the Research Council of Norway (no. 267574).

Financial support. This research has been supported by the NMBU (grant no. 1205051013), the Research Council of Norway (grant no. 267574), and the NILU (grant nos. B111088 and B116037).

Review statement. This paper was edited by Ralf Ebinghaus and reviewed by two anonymous referees.

\section{References}

Alam, M. S., Delgado-Saborit, J. M., Stark, C., and Harrison, R. M.: Investigating PAH relative reactivity using congener profiles, quinone measurements and back trajectories, Atmos. Chem. Phys., 14, 2467-2477, https://doi.org/10.5194/acp-142467-2014, 2014.

AMAP: Arctic Pollution 2009, Arctic Monitoring and Assessment Programme, Oslo, Norway, 1-83, 2009.

AMAP: AMAP Assessment 2016: Chemicals of Emerging Arctic Concern., Arctic Monitoring and Assessment Programme (AMAP), Oslo, Norway, xvi + 353 pp., 2017.

AMAP: Arctic Monitoring and Assessment Programme - an Arctic Council Working Group, available at: https://www.amap.no/ (last access: 7 February 2020), 2019.

Bahm, K. and Khalil, M. A. K.: A new model of tropospheric hydroxyl radical concentrations, Chemosphere, 54, 143-166, https://doi.org/10.1016/j.chemosphere.2003.08.006, 2004.

Barrie, L. A., Gregor, D., Hargrave, B., Lake, R., Muir, D., Shearer, R., Tracey, B., and Bidleman, T.: Arctic contaminants: sources, occurrence and pathways, Sci. Total Environ., 122, 174, https://doi.org/10.1016/0048-9697(92)90245-N, 1992.

Bendig, P., Hägele, F., and Vetter, W.: Widespread occurrence of polyhalogenated compounds in fat from kitchen hoods, Anal. Bioanal. Chem., 405, 7485-7496, https://doi.org/10.1007/s00216-013-7194-5, 2013.

Beyer, A., Wania, F., Gouin, T., Mackay, D., and Matthies, M.: Temperature Dependence of the Characteristic Travel Distance, Environ. Sci. Technol., 37, 766-771, https://doi.org/10.1021/es025717w, 2003.

Bidleman, T. F., Brorström-Lundén, E., Hansson, K., Laudon, H., Nygren, O., and Tysklind, M.: Atmospheric Transport and Deposition of Bromoanisoles Along a Temperate to Arctic Gradient, Environ. Sci. Technol., 51, 10974-10982, https://doi.org/10.1021/acs.est.7b03218, 2017a.

Bidleman, T. F., Laudon, H., Nygren, O., Svanberg, S., and Tysklind, M.: Chlorinated pesticides and natural brominated anisoles in air at three northern Baltic stations, Environ. Pollut., 225, 381-389, https://doi.org/10.1016/j.envpol.2017.02.064, 2017b.

Brown, T. N. and Wania, F.: Screening chemicals for the potential to be persistent organic pollutants: A case study of Arctic contaminants, Environ. Sci. Technol., 42, 5202-5209, https://doi.org/10.1021/es8004514, 2008.

ChemAxon: JChem for Excel Add-In V 19.25.0.559., available at: https://chemaxon.com/, last access: 19 December 2019.

Coscollà, C., Castillo, M., Pastor, A., and Yusà, V.: Determination of 40 currently used pesticides in airborne particulate matter (PM 10) by microwave-assisted extraction and gas chromatography coupled to triple quadrupole mass spectrometry, Anal. Chim. Acta, 693, 72-81, https://doi.org/10.1016/j.aca.2011.03.017, 2011.

Czech, H., Miersch, T., Orasche, J., Abbaszade, G., Sippula, O., Tissari, J., Michalke, B., Schnelle-Kreis, J., Streibel, T., Jokiniemi, J., and Zimmermann, R.: Chemical composition and speciation of particulate organic matter from modern residential small-scale wood combustion appliances, Sci. Total Environ., 612, 636-648, https://doi.org/10.1016/j.scitotenv.2017.08.263, 2018.

Czub, G., Wania, F., and McLachlan, M. S.: Combining LongRange Transport and Bioaccumulation Considerations to Identify Potential Arctic Contaminants, Environ. Sci. Technol., 42, 3704-3709, https://doi.org/10.1021/es7028679, 2008.

Drotikova, T., Ali, A. M., Halse, A. K., Reinardy, H. C., and Kallenborn, R.: Polycyclic aromatic hydrocarbons (PAHs), oxy- and nitro-PAHs in ambient air of Arctic town Longyearbyen, Svalbard, Atmos. Chem. Phys. Discuss., https://doi.org/10.5194/acp2020-142, in review, 2020.

ECHA: Mapping the chemical universe to address substances of concern - Integrated Regulatory Strategy Annual Report 2019, ECHA, Finland, 1-59, 2019a.

ECHA: ECHA substance information 3-iodo-2-propynyl butylcarbamate, available at: https://echa.europa.eu/ substance-information/-/substanceinfo/100.054.188 (last access: 7 February 2020), 2019b.

ECHA: ECHA substance information Caffeine, available at: https://echa.europa.eu/substance-information/-/substanceinfo/ 100.000.329 (last access: 7 February 2020), 2019c.

ECHA: ECHA substance information Dichlofluanid, available at: https://echa.europa.eu/substance-information/-/substanceinfo/ 100.012.835 (last access: 7 February 2020), 2019d.

ECHA: ECHA substance information Benzenesulfonamide, available at: https://echa.europa.eu/substance-information/-/ substanceinfo/100.002.398 (last access: 7 February 2020), 2019e.

ECHA: ECHA substance information Nitrapyrin, available at: https://echa.europa.eu/substance-information/-/substanceinfo/ 100.016.076 (last access: 7 February 2020), 2019f.

ECHA: ECHA substance information Dichlorobenil, available at: https://echa.europa.eu/substance-information/-/substanceinfo/ 100.013.443 (last access: 7 February 2020), 2019g. 
ECHA: ECHA substance information 2-Methylanthraquinone, available at: https://echa.europa.eu/substance-information/-/ substanceinfo/100.001.399 (last access: 7 February 2020), 2019h.

ECHA: ECHA substance information Tris(2-chloro-1methylethyl) phosphate, available at: https://echa.europa. eu/substance-information/-/substanceinfo/100.033.766 (last access: 7 February 2020), 2019 i.

Elix, J. A., Whitton, A. A., and Sagent, M. V.: Recent Progress in the Chemistry of Lichen Substances, in: Progress in the Chemistry of Organic Natural Products, edited by: Herz, W., Grisebach, H., and Kirby, G. W., Springer-Verlag, Vienna, Austria, 103-234, 1984.

EMEP: The co-operative programme for monitoring and evaluation of the long-range transmission of air pollutants in Europe (inofficially "European Monitoring and Evaluation Programme" = EMEP) is a scientifically based and policy driven programme under the Convention on Long-range Transboundary Air Pollution (CLRTAP) for international co-operation to solve transboundary air pollution problems, available at: http://www.emep.int (last access: 7 February 2020), 2019.

European Parliament: Regulation (EC) No. 1907/2006 of the European Parliament and of the Council, 18 December 2006, concerning the Registration, Evaluation, Authorisation and Restriction of Chemicals (REACH), establishing a European Chemicals Agency, amending Directive 1999/45/EC and repealing Council Regulation (EEC) No. 793/93 and Commission Regulation (EC) No. 1488/94 as well as Council Directive 76/769/EEC and Commission Directives 91/155/EEC, 93/67/EEC, 93/105/EC and 2000/21/EC. The European Parliament and the Council of the European Union, 2018.

Fiedler, H., Kallenborn, R., de Boer, J., and Sydnes Leiv, K.: The Stockholm Convention: A Tool for the Global Regulation of Persistent Organic Pollutants, Chemistry International, 41, 4-11, https://doi.org/10.1515/ci-2019-0202, 2019.

Führer, U. and Ballschmiter, K.: Bromochloromethoxybenzenes in the Marine Troposphere of the Atlantic Ocean:? A Group of Organohalogens with Mixed Biogenic and Anthropogenic Origin, Environ. Sci. Technol., 32, 2208-2215, https://doi.org/10.1021/es970922a, 1998.

Genualdi, S., Harner, T., Cheng, Y., MacLeod, M., Hansen, K. M., van Egmond, R., Shoeib, M., and Lee, S. C.: Global Distribution of Linear and Cyclic Volatile Methyl Siloxanes in Air, Environ. Sci. Technol., 45, 3349-3354, https://doi.org/10.1021/es200301j, 2011.

GovCanada: Chemicals of high priority, Batch 8 of the Challenge: Tetrachloroveratrole, available at: https://www.canada.ca/en/ health-canada/services/chemical-substances/challenge/batch-8/ tetrachloroveratrole.html (last access: 7 February 2020), 2019.

Grazulevicius, J. V., Strohriegl, P., Pielichowski, J., and Pielichowski, K.: Carbazole-containing polymers: synthesis, properties and applications, Prog. Polym. Sci., 28, 1297-1353, https://doi.org/10.1016/S0079-6700(03)00036-4, 2003.

Gubala, C. P., Landers, D. H., Monetti, M., Heit, M., Wade, T., Lasorsa, B., and Allen-Gil, S.: The rates of accumulation and chronologies of atmospherically derived pollutants in Arctic Alaska, USA, Sci. Total Environ., 160-161, 347-361, https://doi.org/10.1016/0048-9697(95)04368-B, 1995.
Hansen, B. G., Munn, S. J., Pakalin, S., Heidorn, C. J. A., Allanou, R., Scheer S., Pellegrini, G., Vegro, S., De Bruijn, J., Luotamo, M., Vormann, K., Loonen, H., Berthault, F., and Praderio, L.: EUR 19757 EN - European Union Risk Assessment Report 4Choro-o-cresol, Office for Official Publications of the European Communities, Luxembourg, 2002.

Health Council of the Netherlands: Committee on Updating of Occupational Exposure Limits. o-, m-, p-Terphenyl (mixture); Health-based Reassessment of Administrative Occupational Exposure Limits. Health Council of the Netherlands, The Hague, the Netherlands, 2002.

Herrero, P., Borrull, F., Pocurull, E., and Marcé, R. M.: An overview of analytical methods and occurrence of benzotriazoles, benzothiazoles and benzenesulfonamides in the environment, TrAC-Trend. Anal. Chem., 62, 46-55, https://doi.org/10.1016/j.trac.2014.06.017, 2014.

Hilton, D. C., Jones, R. S., and Sjödin, A.: A method for rapid, non-targeted screening for environmental contaminants in household dust, J. Chromatogr. A, 1217, 6851-6856, https://doi.org/10.1016/j.chroma.2010.08.039, 2010.

Hoferkamp, L., Hermanson, M. H., and Muir, D. C. G.: Current use pesticides in Arctic media; 2000-2007, Sci. Total Environ., 408, 2985-2994, https://doi.org/10.1016/j.scitotenv.2009.11.038, 2010.

Howard, P. H. and Muir, D. C. G.: Identifying New Persistent and Bioaccumulative Organics Among Chemicals in Commerce, Environ. Sci. Technol., 44, 2277-2285, https://doi.org/10.1021/es903383a, 2010.

Hung, H., Kallenborn, R., Breivik, K., Su, Y., Brorström-Lundén, E., Olafsdottir, K., Thorlacius, J. M., Leppänen, S., Bossi, R., Skov, H., Manø, S., Patton, G. W., Stern, G., Sverko, E., and Fellin, P.: Atmospheric monitoring of organic pollutants in the Arctic under the Arctic Monitoring and Assessment Programme (AMAP): 1993-2006, Sci. Total Environ., 408, 2854-2873, https://doi.org/10.1016/j.scitotenv.2009.10.044, 2010.

Ireland/UK: European Union Risk Assessment Report tris(2chloro-1-methylethyl) phosphate. Office for Official Publications of the European Communities, Luxembourg, 2008.

Kallenborn, R., Breivik, K., Eckhardt, S., Lunder, C. R., Manø, S., Schlabach, M., and Stohl, A.: Long-term monitoring of persistent organic pollutants (POPs) at the Norwegian Troll station in Dronning Maud Land, Antarctica, Atmos. Chem. Phys., 13, 6983-6992, https://doi.org/10.5194/acp-13-6983-2013, 2013.

Kallenborn, R., Brorström-Lundén, E., Reiersen, L.-O., and Wilson, S.: Pharmaceuticals and personal care products (PPCPs) in Arctic environments: indicator contaminants for assessing local and remote anthropogenic sources in a pristine ecosystem in change, Environ. Sci. Pollut. R., 25, 33001-33013, https://doi.org/10.1007/s11356-017-9726-6, 2018.

Karavalakis, G., Fontaras, G., Ampatzoglou, D., Kousoulidou, M., Stournas, S., Samaras, Z., and Bakeas, E.: Effects of low concentration biodiesel blends application on modern passenger cars. Part 3: Impact on PAH, nitro-PAH, and oxy-PAH emissions, Environ. Pollut., 158, 1584-1594, https://doi.org/10.1016/j.envpol.2009.12.017, 2010.

Kirchner, M., Jakobi, G., Körner, W., Levy, W., Moche, W., Niedermoser, B., Schaub, M., Ries, L., Weiss, P., Antritter, F., Fischer, N., Henkelmann, B., and Schramm, K.-W.: Ambient Air Levels of Organochlorine Pesticides at Three 
High Alpine Monitoring Stations: Trends and Dependencies on Geographical Origin, Aerosol Air Qual. Res., 16, 738-751, https://doi.org/10.4209/aaqr.2015.04.0213, 2016.

Koziol, A. S. and Pudykiewicz, J. A.: Global-scale environmental transport of persistent organic pollutants, Chemosphere, 45, 1181-1200, https://doi.org/10.1016/S0045-6535(01)000042, 2001.

Labmonk: Labmonk: Synthesis of 2,4,6-tribromoaniline from aniline, available at: https://labmonk.com/ synthesis-of-2-4-6-tribromoaniline-from-aniline (last access: 7 February 2020), 2019.

Lebedev, A. T., Mazur, D. M., Polyakova, O. V., Kosyakov, D. S., Kozhevnikov, A. Y., Latkin, T. B., Andreeva Yu, I., and Artaev, V. B.: Semi volatile organic compounds in the snow of Russian Arctic islands: Archipelago Novaya Zemlya, Environ. Pollut., 239, 416-427, https://doi.org/10.1016/j.envpol.2018.03.009, 2018.

Leng, G. and Gries, W.: New specific and sensitive biomonitoring methods for chemicals of emerging health relevance, Int. J. Hyg. Envir. Heal., 220, 113-122, https://doi.org/10.1016/j.ijheh.2016.09.014, 2017.

Lui, K. H., Bandowe, B. A., Tian, L., Chan, C. S., Cao, J. J., Ning, Z., Lee, S. C., and Ho, K. F.: Cancer risk from polycyclic aromatic compounds in fine particulate matter generated from household coal combustion in Xuanwei, China, Chemosphere, 169, 660-668, https://doi.org/10.1016/j.chemosphere.2016.11.112, 2017.

Macdonald, R. W., Barrie, L. A., Bidleman, T. F., Diamond, M. L., Gregor, D. J., Semkin, R. G., Strachan, W. M. J., Li, Y. F., Wania, F., Alaee, M., Alexeeva, L. B., Backus, S. M., Bailey, R., Bewers, J. M., Gobeil, C., Halsall, C. J., Harner, T., Hoff, J. T., Jantunen, L. M. M., Lockhart, W. L., Mackay, D., Muir, D. C. G., Pudykiewicz, J., Reimer, K. J., Smith, J. N., Stern, G. A., Schroeder, W. H., Wagemann, R., and Yunker, M. B.: Contaminants in the Canadian Arctic: 5 years of progress in understanding sources, occurrence and pathways, Sci. Total Environ., 254, 93-234, https://doi.org/10.1016/S0048-9697(00)00434-4, 2000.

Macdonald, R. W., Harner, T., and Fyfe, J.: Recent climate change in the Arctic and its impact on contaminant pathways and interpretation of temporal trend data, Sci. Total Environ., 342, 5-86, https://doi.org/10.1016/j.scitotenv.2004.12.059, 2005.

MacLeod, M., Riley, W. J., and McKone, T. E.: Assessing the Influence of Climate Variability on Atmospheric Concentrations of Polychlorinated Biphenyls Using a Global-Scale Mass Balance Model (BETR-Global), Environ. Sci. Technol., 39, 6749-6756, https://doi.org/10.1021/es048426r, 2005.

Mazur, D. M., Zenkevich, I. G., Artaev, V. B., Polyakova, O. V., and Lebedev, A. T.: Regression algorithm for calculating second-dimension retention indices in comprehensive twodimensional gas chromatography, J. Chromatogr. A, 1569, 178185, https://doi.org/10.1016/j.chroma.2018.07.038, 2018.

Meng, J.: Production of dacthal from xylene. Copyright () 2019 American Chemical Society (ACS). All Rights Reserved., Patent CN102432470A, Peop. Rep. China, 2012.

Messing, P. G., Farenhorst, A., Waite, D. T., and Sproull, J. F.: Air concentrations of currently used herbicides and legacy compounds in the Canadian prairies, subarctic, and arctic, J. Environ. Sci. Heal. B, 49, 338-343, https://doi.org/10.1080/03601234.2014.882163, 2014.
MetFrag: MetFrag webtool, available at: https://msbi.ipb-halle.de/ MetFragBeta/ (last access: 7 February 2020), 2019.

Moltó, J., Font, R., and Conesa, J. A.: Study of the Organic Compounds Produced in the Pyrolysis and Combustion of Used Polyester Fabrics, Energ. Fuel., 20, 1951-1958, https://doi.org/10.1021/ef060205e, 2006.

Moltó, J., Font, R., Gálvez, A., and Conesa, J. A.: Pyrolysis and combustion of electronic wastes, J. Anal. Appl. Pyrol., 84, 6878, https://doi.org/10.1016/j.jaap.2008.10.023, 2009.

Muir, D. C. G. and Howard, P. H.: Are there other persistent organic pollutants? A challenge for environmental chemists, Environ. Sci. Technol., 40, 7157-7166, https://doi.org/10.1021/es061677a, 2006.

Naccarato, A., Gionfriddo, E., Sindona, G., and Tagarelli, A.: Simultaneous determination of benzothiazoles, benzotriazoles and benzosulfonamides by solid phase microextraction-gas chromatography-triple quadrupole mass spectrometry in environmental aqueous matrices and human urine, J. Chromatogr. A, 1338, 164-173, https://doi.org/10.1016/j.chroma.2014.02.089, 2014.

Nizzetto, P. B. and Aas, W.: Monitoring of environmental contaminants in air and precipitation. Annual report 2015, NILU, Kjeller, Norway, M-579, 1-98, 2016.

Nizzetto, P. B., Aas, W., and Warner, N.: Monitoring of environmental contaminants in air and precipitation. Annual report 2017, NILU, Kjeller, Norway M-1062, 1-142, 2018.

NORMAN network: List of emergin substances, latest update February 2016, available at: https://www.norman-network. com/sites/default/files/files/Emerging_substances_list_Feb_16/ NORMANlist_2016_FINAL.XLSX (last access: 7 February 2020), 2016.

Oulton, S.: Scientific working group for the analysis of seized drugs, available at: http://swgdrug.org/ms.htm (last access: 7 February 2020), 2019.

PerkinElmerInformatics: ChemOffice19: ChemDraw for Excel V 19.0., available at: https://www.perkinelmer.com (last access: 4 February 2020), 2019.

Reppas-Chrysovitsinos, E., Sobek, A., and MacLeod, M.: Screening-level exposure-based prioritization to identify potential POPs, vPvBs and planetary boundary threats among Arctic contaminants, Emerging Contaminants, 3, 85-94, https://doi.org/10.1016/j.emcon.2017.06.001, 2017.

Röhler, L., Bohlin-Nizzetto, P., Rostkowski, P., Kallenborn, R., and Schlabach, M.: Non-target and suspect characterisation of organic contaminants in ambient air, Part I: Combining a novel sample clean-up method with comprehensive twodimensional gas chromatography, Atmos. Chem. Phys. Discuss., https://doi.org/10.5194/acp-2020-263, in review, 2020.

Ruttkies, C., Schymanski, E. L., Wolf, S., Hollender, J., and Neumann, S.: MetFrag relaunched: incorporating strategies beyond in silico fragmentation, J. Cheminformatics, 8, 1-16, https://doi.org/10.1186/s13321-016-0115-9, 2016.

Salamova, A., Hermanson, M. H., and Hites, R. A.: Organophosphate and Halogenated Flame Retardants in Atmospheric Particles from a European Arctic Site, Environ. Sci. Technol., 48, 6133-6140, https://doi.org/10.1021/es500911d, 2014.

Samokhin, A., Sotnezova, K., Lashin, V., and Revelsky, I.: Evaluation of mass spectral library search algorithms implemented 
in commercial software, J. Mass Spectrom., 50, 820-825, https://doi.org/10.1002/jms.3591, 2015.

Schenker, U., Scheringer, M., and Hungerbühler, K.: Including degradation products of persistent organic pollutants in a global multi-media box model, Environ. Sci. Pollut. R. - International, 14, 145-152, https://doi.org/10.1065/espr2007.03.398, 2007.

Schymanski, E. L., Singer, H. P., Slobodnik, J., Ipolyi, I. M., Oswald, P., Krauss, M., Schulze, T., Haglund, P., Letzel, T., Grosse, S., Thomaidis, N. S., Bletsou, A., Zwiener, C., Ibanez, M., Portoles, T., de Boer, R., Reid, M. J., Onghena, M., Kunkel, U., Schulz, W., Guillon, A., Noyon, N., Leroy, G., Bados, P., Bogialli, S., Stipanicev, D., Rostkowski, P., and Hollender, J.: Non-target screening with high-resolution mass spectrometry: critical review using a collaborative trial on water analysis, Anal. Bioanal. Chem., 407, 6237-6255, https://doi.org/10.1007/s00216-015-8681-7, 2015.

Singh, D. K., Kawamura, K., Yanase, A., and Barrie, L. A.: Distributions of Polycyclic Aromatic Hydrocarbons, Aromatic Ketones, Carboxylic Acids, and Trace Metals in Arctic Aerosols: Long-Range Atmospheric Transport, Photochemical Degradation/Production at Polar Sunrise, Environ. Sci. Technol., 51, 8992-9004, https://doi.org/10.1021/acs.est.7b01644, 2017.

Stefanye, D.: Bluing of steel surfaces. Copyright (C) 2019 American Chemical Society (ACS). All Rights Reserved., Patent US3677829A, 1972.

Stiborova, M.: Nitroaromatic compounds: Environmental pollutants with carcinogenic potential for humans, Chem. Listy, 96, 784791, 2002.

Su, Y., Hung, H., Blanchard, P., Patton, G. W., Kallenborn, R., Konoplev, A., Fellin, P., Li, H., Geen, C., Stern, G., Rosenberg, B., and Barrie, L. A.: A circumpolar perspective of atmospheric organochlorine pesticides (OCPs): Results from six Arctic monitoring stations in 2000-2003, Atmos. Environ., 42, 4682-4698, https://doi.org/10.1016/j.atmosenv.2008.01.054, 2008.

Sühring, R., Diamond, M. L., Scheringer, M., Wong, F., Pućko, M., Stern, G., Burt, A., Hung, H., Fellin, P., Li, H., and Jantunen, L. M.: Organophosphate Esters in Canadian Arctic Air: Occurrence, Levels and Trends, Environ. Sci. Technol., 50, 7409-7415, https://doi.org/10.1021/acs.est.6b00365, 2016.

UNECE: The 1998 Aarhus Protocol on Persistent Organic Pollutants (POPs), available at: https://www.unece.org/env/lrtap/ pops_h1.html (last access: 7 February 2020), 1998.

UNEP: The global monitoring plan for persistent organic pollutants (POPs), available at: http://chm.pops.int/Implementation/ GlobalMonitoringPlan/Overview/tabid/83/Default.aspx (last access: 4 February 2020), 2009a.

UNEP: Stockholm Convention on Persistent Organic Pollutants (POPs), available at: http://www.pops.int/TheConvention/ Overview/TextoftheConvention/tabid/2232/Default.aspx (last access: 4 February 2020), 2009b.

U.S. EPA: US EPA 738-F-05-007 R.E.D. Chloroneb, available at: https://www3.epa.gov/pesticides/chem_search/reg_ actions/reregistration/fs_PC-027301_1-Sep-05.pdf (last access: 7 February 2020), 2005.

U.S. EPA: Estimation Programs Interface Suite ${ }^{\mathrm{TM}}$ for Microsoft ${ }^{\circledR}$ Windows, v 4.11. United States Environmental Protection Agency, Washington, D.C., USA, 2019.

Veenaas, C. and Haglund, P.: A retention index system for comprehensive two-dimensional gas chromatography us- ing polyethylene glycols, J. Chromatogr. A, 1536, 67-74, https://doi.org/10.1016/j.chroma.2017.08.062, 2018.

Vetter, W., Schlabach, M., and Kallenborn, R.: Evidence for the presence of natural halogenated hydrocarbons in southern Norwegian and polar air, Fresen. Environ. Bull., 11, 170-175, 2002.

Vetter, W., Rosenfelder, N., Kraan, S., and Hiebl, J.: Structure and origin of the natural halogenated monoterpene MHC-1 and its concentrations in marine mammals and fish, Chemosphere, 73, 7-13, https://doi.org/10.1016/j.chemosphere.2008.06.020, 2008.

Vicente, E. D., Vicente, A. M., Musa Bandowe, B. A., and Alves, C. A.: Particulate phase emission of parent polycyclic aromatic hydrocarbons (PAHs) and their derivatives (alkyl-PAHs, oxygenated-PAHs, azaarenes and nitrated PAHs) from manually and automatically fired combustion appliances, Air Qual. Atmos. Heal., 9, 653-668, https://doi.org/10.1007/s11869-015-0364-1, 2016.

Vorkamp, K. and Rigét, F. F.: A review of new and current-use contaminants in the Arctic environment: Evidence of long-range transport and indications of bioaccumulation, Chemosphere, 111, 379-395, https://doi.org/10.1016/j.chemosphere.2014.04.019, 2014.

Wang, L.: CAS Marks Multiple Milestones, Chem. Eng. News, 93, $1,2015$.

Wang, Z., Li, K., Lambert, P., and Yang, C.: Identification, characterization and quantitation of pyrogenic polycylic aromatic hydrocarbons and other organic compounds in tire fire products, J. Chromatogr. A, 1139, 14-26, https://doi.org/10.1016/j.chroma.2006.10.085, 2007.

Wania, F., Breivik, K., Persson, N. J., and McLachlan, M. S.: CoZMo-POP 2 - A fugacity-based dynamic multicompartmental mass balance model of the fate of persistent organic pollutants, Environ. Model. Softw., 21, 868-884, https://doi.org/10.1016/j.envsoft.2005.04.003, 2006.

Watanabe, M., Nakata, C., Wu, W., Kawamoto, K., and Noma, Y.: Characterization of semi-volatile organic compounds emitted during heating of nitrogen-containing plastics at low temperature, Chemosphere, 68, 2063-2072, https://doi.org/10.1016/j.chemosphere.2007.02.022, 2007.

Webster, E., Mackay, D., and Wania, F.: Evaluating environmental persistence, Environ. Toxicol. Chem., 17, 2148-2158, https://doi.org/10.1002/etc.5620171104, 1998.

Weyer, V., Blettner, M., Cholmakow-Bodechtel, C., and Heudorf, U.: Chemical accident at Hoechst AG Frankfurt/Main, Germany, 1993: a 15 year follow-up analysis of mortality, Eur. J. Epidemiol., 29, 73-76, https://doi.org/10.1007/s10654-013-9870-3, 2014.

WOC: 2,2,4-Trichloroacetophenone Properties, available at: https://www.worldofchemicals.com/chemicals/ chemical-properties/224-trichloroacetophenone.html (last access: 7 February 2020), 2019.

Woodward, E. E., Kolpin, D. W., Zheng, W., Holm, N. L., Meppelink, S. M., Terrio, P. J., and Hladik, M. L.: Fate and transport of nitrapyrin in agroecosystems: Occurrence in agricultural soils, subsurface drains, and receiving streams in the Midwestern US, Sci. Total Environ., 650, 2830-2841, https://doi.org/10.1016/j.scitotenv.2018.09.387, 2019. 
Xiao, H., Shen, L., Su, Y., Barresi, E., DeJong, M., Hung, H., Lei, Y.-D., Wania, F., Reiner, E. J., Sverko, E., and Kang, S.-C.: Atmospheric concentrations of halogenated flame retardants at two remote locations: The Canadian High Arctic and the Tibetan Plateau, Environ. Pollut., 161, 154-161, https://doi.org/10.1016/j.envpol.2011.09.041, 2012.

Zawadzka, K., Bernat, P., Felczak, A., and Lisowska, K.: Carbazole hydroxylation by the filamentous fungi of the Cunninghamella species, Environ. Sci. Pollut. R. - International, 22, 1965819666, https://doi.org/10.1007/s11356-015-5146-7, 2015.

Zhang, X., Brown, T. N., Wania, F., Heimstad, E. S., and Goss, K.U.: Assessment of chemical screening outcomes based on different partitioning property estimation methods, Environ. Int., 36, 514-520, https://doi.org/10.1016/j.envint.2010.03.010, 2010.
Zhao, X., Chaudhry, S. T., and Mei, J.: Chapter Five - Heterocyclic Building Blocks for Organic Semiconductors, Adv. Heterocycl. Chem., 121, 133-171, https://doi.org/10.1016/bs.aihch.2016.04.009, 2017.

Zhong, G., Xie, Z., Cai, M., Möller, A., Sturm, R., Tang, J., Zhang, G., He, J., and Ebinghaus, R.: Distribution and Air-Sea Exchange of Current-Use Pesticides (CUPs) from East Asia to the High Arctic Ocean, Environ. Sci. Technol., 46, 259-267, https://doi.org/10.1021/es202655k, 2012. 